Edith Cowan University

Research Online

Research outputs 2014 to 2021

2019

Enhancing heat pipe solar water heating systems performance using a novel variable mass flow rate technique and different solar working fluids

\author{
Abdellah Shafieian \\ Edith Cowan University \\ Junaid Jaffer Osman \\ Edith Cowan University \\ Mehdi Khiadani \\ Edith Cowan University \\ Ataollah Nosrati \\ Edith Cowan University
}

Follow this and additional works at: https://ro.ecu.edu.au/ecuworkspost2013

Part of the Energy Systems Commons

10.1016/j.solener.2019.05.016

This is an Author's Accepted Manuscript of:

Shafieian, A., Osman, J. J., Khiadani, M., \& Nosrati, A. (2019). Enhancing heat pipe solar water heating systems performance using a novel variable mass flow rate technique and different solar working fluids. Solar Energy, 186, 191-203.

https://doi.org/10.1016/j.solener.2019.05.016

This Journal Article is posted at Research Online.

https://ro.ecu.edu.au/ecuworkspost2013/6242 
This article has been published as Shafieian, A., Osman, J. J., Khiadani, M., \& Nosrati, A. (2019). Enhancing heat pipe solar water heating systems performance using a novel variable mass flow rate technique and different solar working fluids. Solar Energy, 186, 191-203. doi:10.1016/j.solener.2019.05.016

This manuscript version is made available under the CC-BY-NC-ND 4.0 license http://creativecommons.org/licenses/by-nc-nd/4.0/

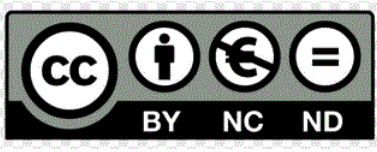

\section{Enhancing heat pipe solar water heating systems performance \\ using a novel variable mass flow rate technique and different}

\section{solar working fluids}

Abdellah Shafieian, PhD Candidate, School of Engineering, Edith Cowan University, 270 Joondalup Drive, Joondalup, Perth, WA 6027, Australia

Email: a.shafieiandastjerdi@ecu.edu.au

Junaid Jaffer Osman, Honor Student, School of Engineering, Edith Cowan University, 270 Joondalup Drive, Joondalup, Perth, WA 6027, Australia

Email: josman@our.ecu.edu.au

Mehdi Khiadani, Associate Professor, School of Engineering, Edith Cowan University, 270 Joondalup Drive, Joondalup, Perth, WA 6027, Australia.

Tel.: +61 86304 5825; fax: +61863045811.

Email: m.khiadani@ecu.edu.au (author for correspondence)

Ataollah Nosrati, Lecturer, School of Engineering, Edith Cowan University, 270

Joondalup Drive, Joondalup, Perth, WA 6027, Australia

Email: a.nosrati@ecu.edu.au 


\begin{abstract}
This paper aims to improve the overall efficiency of heat pipe solar water heating (HPSWH) systems by implementing a novel variable mass flow rate technique which regulates the solar working fluid mass flow rate of the system with the solar radiation intensity. To analyze the system under real operational conditions, the residential hot water consumption pattern of Perth residents in Western Australia was used in the experiments. In addition, a nanofluid $\left(\mathrm{Al}_{2} \mathrm{O}_{3} / \mathrm{DI}\right)$ was fabricated and its performance as the solar working fluid was investigated to find the optimum concentration and to confirm its stability and thermo-physical properties consistency. The HPSWH system was operated during three days having similar climatic conditions using distilled water at a constant mass flow rate (Case I), the optimized nanofluid at a constant mass flow rate (Case II), and the optimized nanofluid at a variable mass flow rate (Case III). The results revealed that $0.1 \mathrm{wt}$ \% Sodium Dodecyl BenzeneSulfonate (SDBS) was the optimum concentration of SDBS for $0.05 \mathrm{wt} \% \mathrm{Al}_{2} \mathrm{O}_{3} / \mathrm{DI}$ water nanofluid at which it exhibited the highest thermal conductivity enhancement and stability. Moreover, the transferred energy to the solar working fluid in Cases II and III were respectively $8.9 \%$ and $22.7 \%$ higher than Case I. The system had respectively $12.46 \%$ and $19.34 \%$ higher thermal efficiencies in Cases II and III compared with Case I. The exergy efficiency improvement of Cases II and III were respectively $1.58 \%$ and $2.66 \%$ compared with Case I. Overall, the results proved the significant effectiveness of the variable mass flow rate technique to improve the thermal performance of HPSWH systems.
\end{abstract}

Keywords: Solar collector; Efficiency; Heat pipe; Water heating; Nanofluid 


\section{Introduction}

Heat pipe solar collectors (HPSCs) are the integration of heat pipe technology with evacuated glass tubes designed to overcome the drawbacks of conventional solar collectors. HPSCs have low thermal and hydraulic resistances, low heat loss, uniform working fluid flow, almost isothermal heat absorption process, and high efficiency even in non-ideal climatic conditions (Chopraa et al., 2018; Hussein et al., 2006; Reay and Kew, 2013; Yu and Xie, 2012 ). Many studies have analyzed the performance of HPSCs and evidenced their significant advantages over conventional types of solar collectors (Azad, 2018; Chow et al., 2013; Han et al., 2009; Hayek et al., 2011; Ismail and Abogderah, 1998; Sabiha et al., 2015; Zambolin and Col, 2010). In a comprehensive comparative study, Ayompe et al. compared the performances of HPSCs and flat plate collectors in daily, monthly, and yearly bases. The annual system efficiency, solar fraction, and collector efficiency of the system using the HPSC were respectively $12 \%, 1.6 \%$, and $4.8 \%$ higher than the flat plate system (Ayompe et al., 2011). As a result of their unique advantages, HPSCs have attracted many researchers to implement them in solar water heating systems.

Kumar et al. used a theoretical approach to model the heat transfer processes in a HPSWH system based on thermal resistances network. The results showed that solar radiation among the operational parameters and evaporator to condenser length ratio among the physical parameters had the most significant impact on the thermal efficiency of the system (Kumar et al., 2017). Shafieian et al. studied the performance of a HPSWH system during the cold season in Perth, Australia both theoretically and experimentally. The solar working fluid mass flow rate in this study was $2 \mathrm{~L} / \mathrm{min}$ and the results showed that the optimum number of vacuum glass tubes under the specific non-ideal climatic conditions was 25 (Shafieian et al., 2019b).

$\mathrm{Du}$ et al. built an experimental rig to investigate the effect of operational parameters on instantaneous efficiency, collector outlet temperature, and pressure drop of a HPSWH system 
(Du et al., 2013). In a similar study, the thermal performance of a HPSWH system was analyzed under weather conditions of Sannandaj, Iran both theoretically and experimentally. The solar working fluid mass flow rate was set at the constant value of $1.1 \mathrm{~L} / \mathrm{min}$ in this study and the highest reached temperature was around $64{ }^{\circ} \mathrm{C}$ (Daghigh, Roonak and Shafieian, Abdellah, 2016).

Wei et al. proposed a new design of HPSWH system by replacing the separate heat pipes which are located besides each other by one large wickless heat pipe. The thermal efficiency of the system with new configuration reached the maximum value of 66\% (Wei et al., 2013). Deng et al. replaced the conventional heat pipes of a HPSWH system with a micro-channel heat pipe array and studied its effect experimentally. The results showed that the proposed configuration increased the thermal efficiency by $25 \%$ (Deng et al., 2015; Deng et al., 2013). Integration of conventional HPSCs with compound parabolic concentrators (CPCs) was proposed and studied comprehensively by Nkwetta and Smyth. Different parabolic profiles were recommended for different solar applications in these studies (Nkwetta and Smyth, 2012a, b, c).

Nevertheless, the relatively low thermal efficiency of solar systems is still the major challenge of solar industry evidenced by various studies conducted to enhance their overall efficiency. The main focus of these studies has been on the working fluid of HPSWH systems. Esroz experimentally compared the performance of a HPSC running with different solar working fluids including hexane, petroleum ether, methanol, chloroform, acetone, and ethanol. The findings showed that the application of chloroform and acetone resulted in highest energy and exergy efficiency (Ersoz, 2016). Guo et al. focused on the effect of using water-ethanol solution on the start-up speed and heat transfer rate of heat pipes in a HPSWH system. The 40 vol.\% ethanol solution leaded to the best performance of the system (Guo et al., 2010).

Sharafeldin and Grof studied the thermal performance of a HPSWH system using $\mathrm{CeO}_{2}$-water nanofluid as its solar working fluid. The results indicated that the prepared nanofluid enhanced 
the thermal efficiency of the system by $34 \%$ compared with conventional systems (Sharafeldin and Grof, 2018). Chougule et al. used carbon nanotubes/water nanofluid in a HPSWH system and experimentally investigated its performance under different operational conditions. The application of the nanofluid with volume concentration of $0.60 \%$ resulted in the thermal efficiency of 73\% (Chougule et al., 2013 ). Iranmanesh et al. improved the thermal performance of a HPSWH system by using graphene nanoplatelets-water nanofluid. The experimental results indicated that using nanofluid increased the collector outlet temperature and thermal energy gain resulting in thermal efficiency improvement up to 90\% (Iranmanesh et al., 2017).

Zhao et al. conducted comparative experiments with a HPSWH system charged with distilled water and graphene-water nanofluid. The results showed the thermal efficiency enhancement of 10.7-15.1\% upon application of nanofluid as the solar working fluid (Zhao et al., 2018). Saad et al. proposed the application of $\mathrm{AL}_{2} \mathrm{O}_{3}$-water at various nanofluid concentrations in HPSWH systems. The heat transfer process was first simulated using a computational fluid dynamics software and the obtained data were validated with experiments. Using the proposed nanofluid slightly increased the thermal efficiency of the system (Saad et al., 2013). Hussein reviewed the latest applications of nanotechnology in efficiency improvement of solar systems including HPSWH systems (Hussein, 2016). Three comprehensive review papers regarding the recent studies in the field of HPSWH systems can be found in the literature (Chopra et al., 2018; Shafieian et al., 2018, 2019a).

By reviewing the literature, it becomes clear that almost all the conventional solar water heating systems in previous studies have been operated with constant solar working fluid mass flow rates. However, during a significant time of the day, the solar radiation reaches its high values which provides a great potential for harvesting the thermal energy. The solar working fluid mass flow rate has a direct effect on the amount of absorbed energy and if the system is operated with low mass flow rates, all the available thermal energy cannot be absorbed. If the system is 
operated with high mass flow rates, the outlet temperature of the collector cannot meet the requirements of a solar water heating system. Therefore, by taking the dynamic behavior of solar radiation into account, regulating the solar working fluid mass flow rate with the changes in solar radiation throughout the day is likely to play an important role in achieving the optimum performance of these systems. In addition, almost all the previous studies have concluded that nanofluids are a promising technology which have the potential of replacing the conventional fluids in HPSWH systems. However, these studies have not considered two major issues which are concentration optimization and reliability of nanofluids in terms of characteristics consistency. Instead of investigating the stability of the applied nanofluids and consistency of their thermo-physical characteristics, they have relied either on random concentrations of nanoparticles or on the data provided by former studies. Furthermore, almost all the previous studies have neglected the hot water consumption pattern while the main purpose of a solar water heating system is meeting a hot water demand. Therefore, the findings are not in accordance with real operational conditions and provide insufficient information regarding the system performance.

Therefore, this experimental study follows three main objectives: (i) to optimize and characterise a nanofluid to confirm its stability and thermo-physical properties consistency to be used as the solar working fluid of a HPSWH system, (ii) to regulate the mass flow rate of the solar working fluid with solar radiation and study its effect on the efficiency enhancement of a HPSWH system, and (iii) to evaluate the capability of a HPSWH system to meet a real residential hot water demand while it is working with distilled water and nanofluid at constant mass flow rates (Cases I and II) and with nanofluid at a variable mass flow rate (Case III). To achieve these objectives, an $\mathrm{Al}_{2} \mathrm{O}_{3} / \mathrm{DI}$ water nanofluid was fabricated and its performance was investigated to find the optimum concentration and to confirm its stability and thermo-physical properties consistency. Then, an experimental rig (Shafieian et al., 2019b) was built and the 
performance of the HPSWH system to meet a real residential hot water consumption pattern was evaluated during three days having similar climatic conditions under operational conditions of Cases I, II, and III.

\section{Experimental setup and instrumentation}

\subsection{Solar water heating system}

The designed and built heat pipe solar water heating system for this study included: a HPSC; a water storage tank; a power unit; a National Instrument Data Acquisition (NIDAQ); T-type thermocouples; a pump; a flow meter; pipes and fittings; and valves. Figures 1 and 2 show the components of the proposed solar system. A HPSC consists of two main components which are heat pipes and vacuum-sealed glass tubes (Fig. 3). The solar collector absorbs a portion of the stroked solar radiation for vaporizing the heat pipe working fluid. Another portion of the stroked solar radiation is dissipated back into the environment. The vaporized heat pipe working fluid moves along the heat pipe towards the manifold section of the HPSC and exchanges its thermal energy with the solar working fluid passing through the heat pipe condensers positioned along the manifold. By exchanging thermal energy, the heat pipe working fluid turns back to the liquid state and returns to the heat pipe evaporator section. The temperature of the solar working fluid, which circulates using a pump, increases as it passes along the manifold over the heat pipe condensers. The high temperature outlet solar working fluid then enters the copper coil located inside the storage and transfers its heat to the water inside the tank. The heated water at top of the storage tank is extracted according to the domestic hot water consumption pattern and replaced with tap water which is added from the bottom section of the tank. 


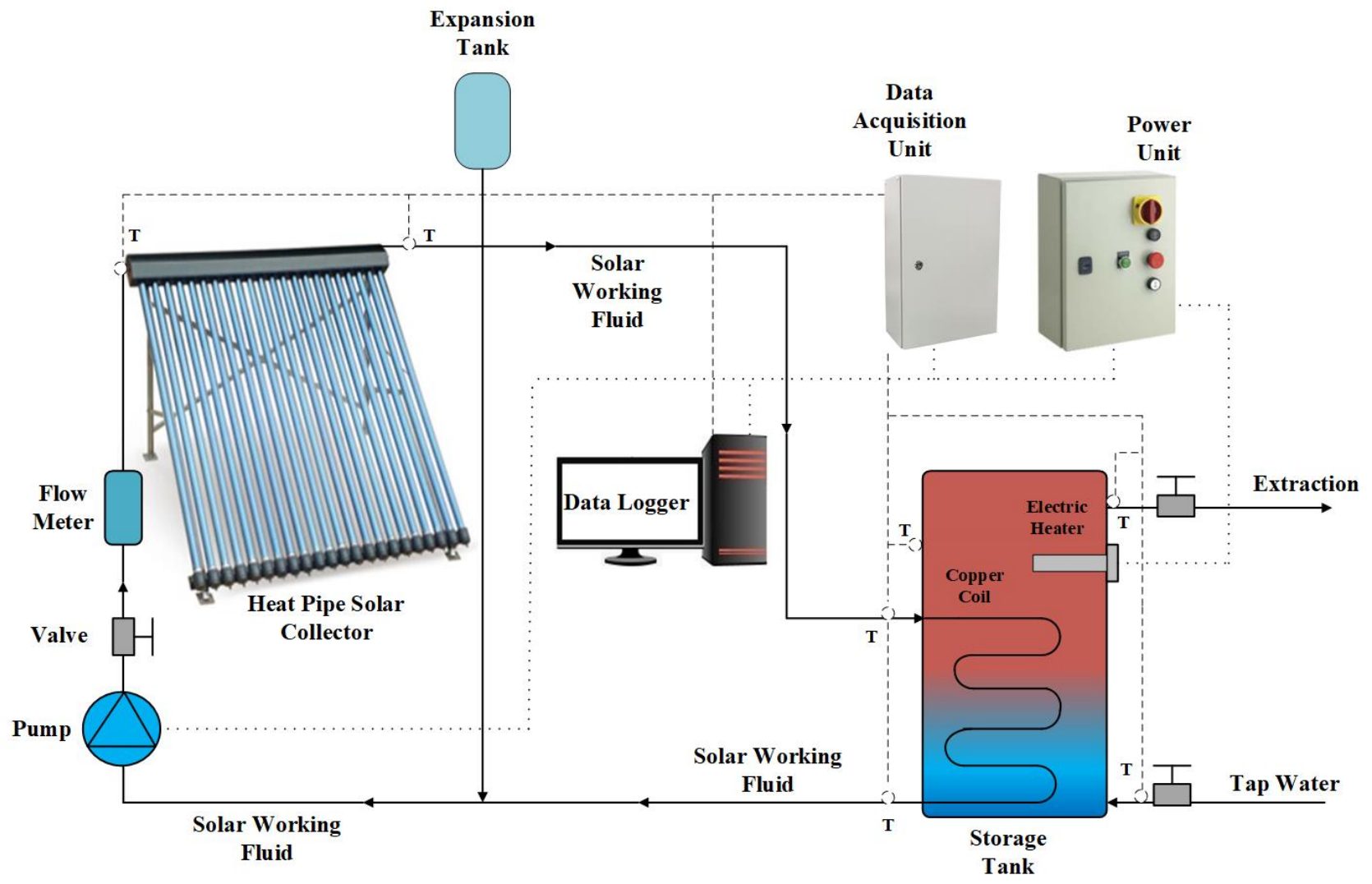

Fig. 1. Schematic diagram of the HPSWH system which was specifically designed and built for this study (Shafieian et al., 2019b). 


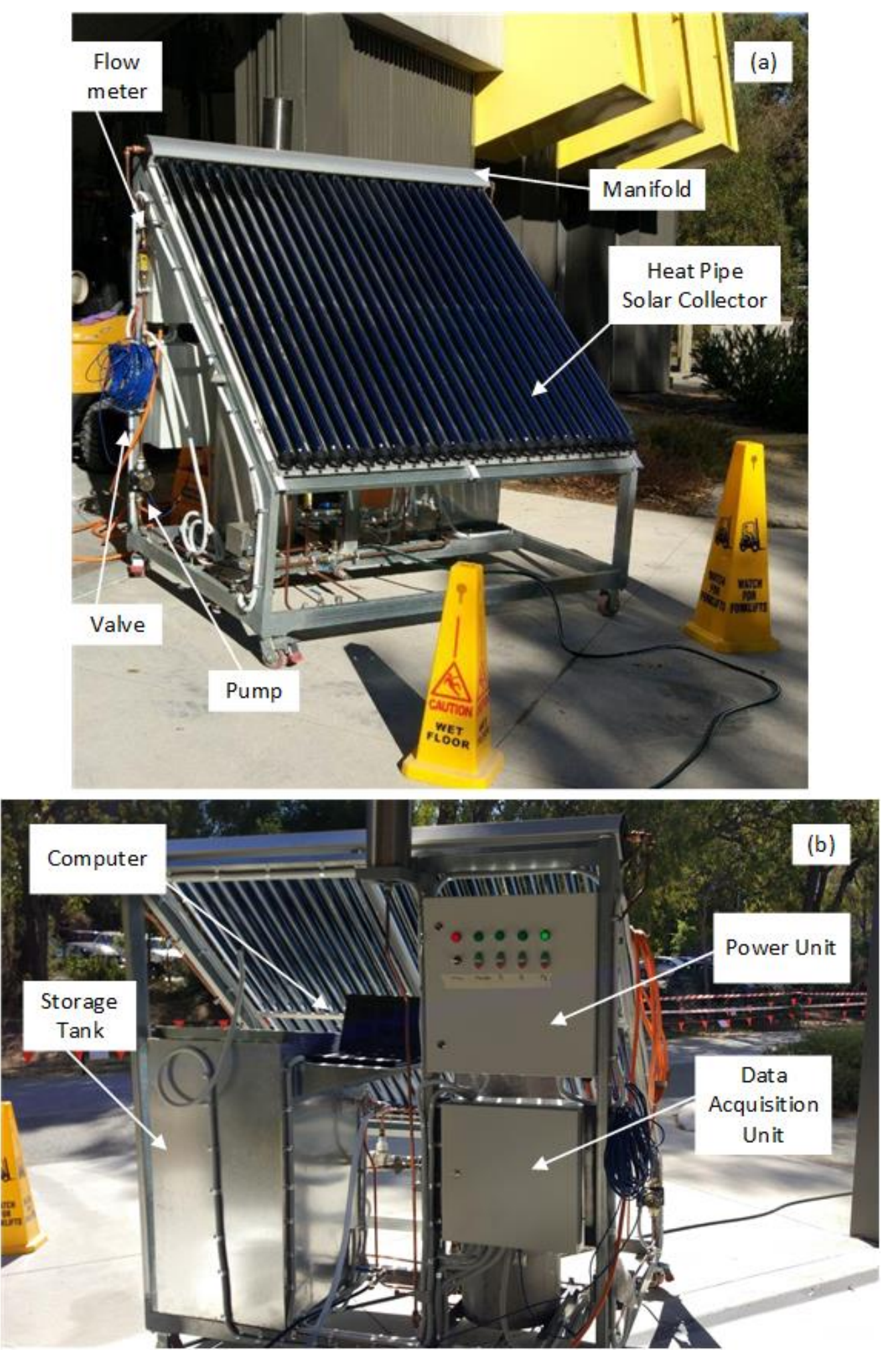

Fig. 2. Experimental setup: (a) front view, (b) back view (Shafieian et al., 2019b). 


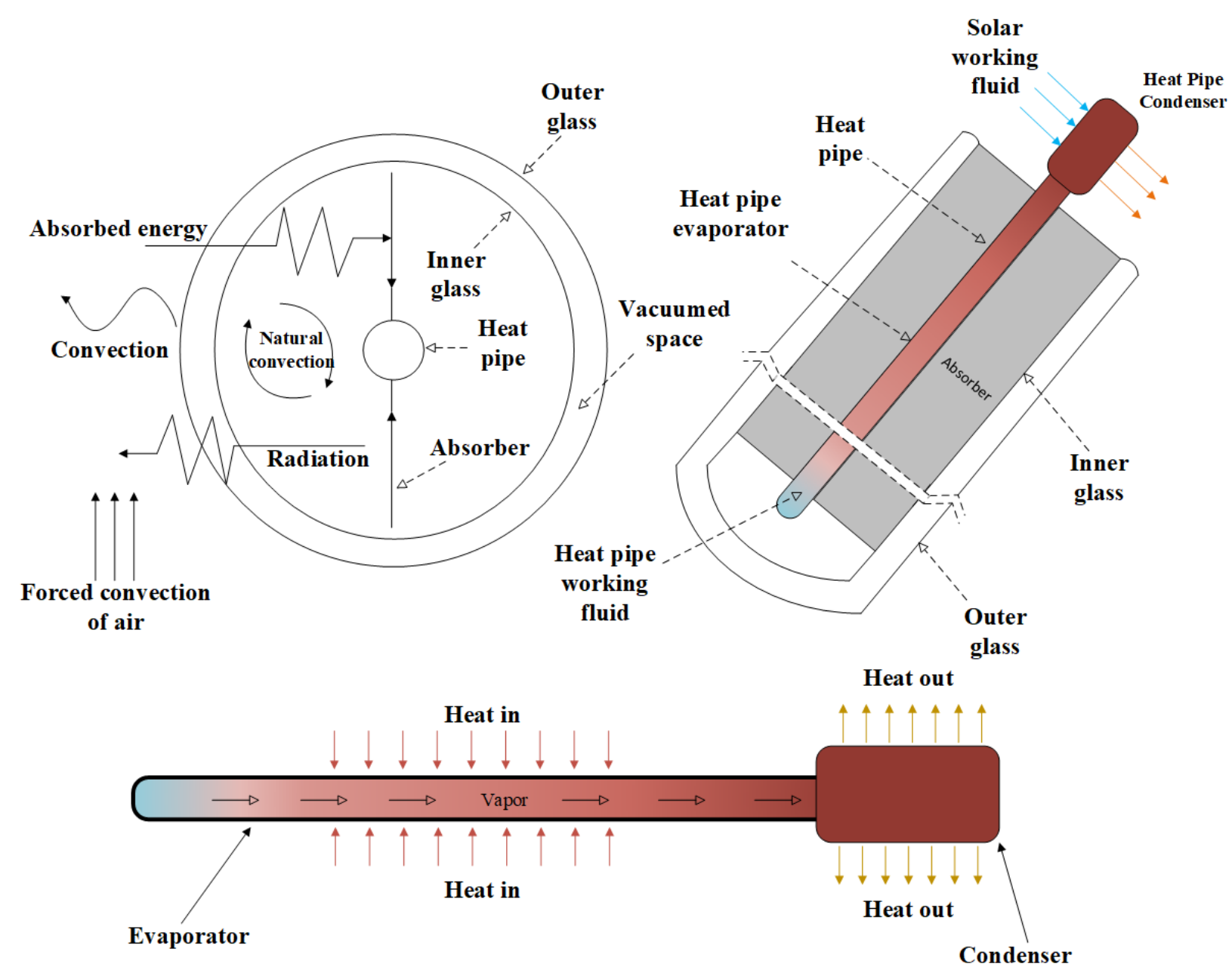

Fig. 3. Schematic diagram of heat transfer processes inside a vacuum tube of a HPSC

(Shafieian et al., 2019b).

The solar working fluid was circulated by a pump made by Davey company and its mass flow rate was regulated using a valve. The quantitative value of the mass flow rate was monitored using a FL-9200 flowmeter made by Omega company. The volume of the storage tank was 210 $\mathrm{L}$ and the length and external heat transfer area of the copper coil inside it was $34 \mathrm{~m}$ and 1.45 $\mathrm{m}^{2}$, respectively. Thermal insulation layers with the overall thickness of $50 \mathrm{~mm}$ were used to insulate the storage tank and minimize heat loss from it. The hot water was extracted according to the domestic hot water consumption pattern using a manual valve and its volume was checked by a scaled container. 
During the experiments, the climatic data such as solar radiation, wind velocity, and ambient temperature were extracted from Edith Cowan University's weather station located in Joondalup which is $23 \mathrm{~km}$ north of Perth business district. The thermocouples used in this study were type T- Class 1 made by TC Ltd. and were monitored using the NIDAQ system. The data was recorded at 10-second intervals using an application program interface (API) which was programmed in the LabVIEW 2014 software. The specifications of the HPSC used in this study, which was purchased from Century Sun Energy Technology Company in China, are presented in Table 1.

Table 1. The specifications of the various components of the HPSC used in this study (Shafieian et al., 2019b).

\begin{tabular}{|c|c|c|c|c|c|}
\hline \multicolumn{2}{|c|}{ Solar collector } & \multicolumn{2}{|c|}{ Heat pipe } & \multicolumn{2}{|c|}{ Vacuum Glass } \\
\hline Number of tubes & 25 & Material & $\begin{array}{c}\text { Red } \\
\text { copper }\end{array}$ & Thickness (m) & 1.60 \\
\hline $\begin{array}{l}\text { Manifold material/ } \\
\text { diameter }(\mathrm{m})\end{array}$ & $\begin{array}{c}\text { red copper/ } \\
0.038\end{array}$ & $\begin{array}{l}\text { Outer } \\
\text { diameter (m) }\end{array}$ & 0.008 & Outer diameter $(\mathrm{m})$ & 0.058 \\
\hline Insulation & $\begin{array}{c}\text { Compressed } \\
\text { Rockwool }\end{array}$ & $\begin{array}{l}\text { Condenser } \\
\text { Length }(\mathrm{m})\end{array}$ & 0.10 & Transmittance & 0.88 \\
\hline Tube length (m) & 1.80 & & & Emissivity & 0.07 \\
\hline Absorptivity & 0.94 & & & & \\
\hline Gross area $\left(\mathrm{m}^{2}\right)$ & 3.93 & & & & \\
\hline
\end{tabular}

\subsection{Experimental procedures}

In order to evaluate the effectiveness of the techniques proposed in this study, three different cases having different solar working fluids and mass flow rates were considered and experiments were conducted throughout three different days with similar climatic conditions. The details of these three cases are presented in Table 2. In Case I, the HPSWH system was filled with distilled water, which is the common solar working fluid in these systems and was operated under constant mass flow rate of $3 \mathrm{~L} / \mathrm{min}$ throughout the day. In Case II, the same procedure was followed but distilled water was replaced by an optimized nanofluid. In Case III, variable mass flow rate of the optimized nanofluid was used and regulated with the solar 
radiation. It is worth noting that the experiments started at 8:45 $\mathrm{AM}$ with collector inlet temperature of $25{ }^{\circ} \mathrm{C}$ and solar working fluid mass flow rate of $3 \mathrm{~L} / \mathrm{min}$ in Cases I and II and $2 \mathrm{~L} / \mathrm{min}$ in Case III.

Table 2. The experimental cases considered for this study

\begin{tabular}{clcc}
\hline Case & Solar working fluid & Mass flow rate (L/min) & Date \\
\hline Case I & Distilled water & Constant (3 L/min) & 20 Sep 2018 \\
Case II & Optimized Nanofluid & Constant (3 L/min) & 21 Sep 2018 \\
& & Variable mass flow rate regulated with solar & 23 Sep 2018 \\
Case III & Optimized Nanofluid & radiation & \\
& & &
\end{tabular}

\subsection{Nanofluid preparation}

Aluminium oxide $\left(\mathrm{Al}_{2} \mathrm{O}_{3}\right)$ nanoparticles (Sigma-Aldrich Pty) having the average size of $13 \mathrm{~nm}$ were used in this study for the purpose of preparation of nanofluids. The density and surface area of the used $\mathrm{Al}_{2} \mathrm{O}_{3}$ nanoparticles were $4.9 \mathrm{~g} / \mathrm{cm}^{3}$ and $85-115 \mathrm{~m}^{2} / \mathrm{g}$, respectively. Deionized (DI) water ( $\mathrm{pH}$ 5.8) produced in situ by the Millipore DirectQ-3UV was used as the base fluid. Sodium Dodecyl BenzeneSulfonate (SDBS) technical grade with the molecular formula of $\mathrm{CH}_{3}\left(\mathrm{CH}_{2}\right)_{11} \mathrm{C}_{6} \mathrm{H}_{4} \mathrm{SO}_{3} \mathrm{Na}$ supplied by Sigma-Aldrich Pty was used as surfactant. pH adjustments were made using very dilute $(0.01 \mathrm{M})$ solutions of $\mathrm{HNO}_{3}$ (RCI Labscan) and $\mathrm{NaOH}$ (Rowe Scientific).

The two-step method was utilised to prepare the $\mathrm{Al}_{2} \mathrm{O}_{3} / \mathrm{DI}$ Water nanofluids (Ali et al., 2018) at ambient temperature $\left(23 \pm 2{ }^{\circ} \mathrm{C}\right)$ with solid concentrations in the range of $0.05-0.1 \mathrm{wt} . \%$. The preparation order was to add a weighed mass of nanoparticles to $100 \mathrm{ml}$ of DI water in a Pyrex glass beaker and disperse them using various techniques including magnetic stirrer, overhead stirrer, sonication bath, sonication bath plus overhead stirrer, and ultrasonic processor. Analyzing the thermo-physical properties of the fabricated nanofluids using the mentioned techniques showed the advantages of sonication/ultrasonication compared with other methods. 
Therefore, the ultrasonication method was applied to fabricate all the $\mathrm{Al}_{2} \mathrm{O}_{3} /$ DI water nanofluids for this study. The nanofluid samples prepared using the ultrasonic processor had elevated temperatures (up to $39^{\circ} \mathrm{C}$ ) and were therefore allowed to cool to ambient temperature before $\mathrm{pH}$ adjustments or any characterisation. The $\mathrm{pH}$ adjusted samples were allowed to equilibrate for 5 mins prior to analysis and acquisition of data.

Three different methods of SDBS addition were initially tested and analysed in order to observe the effect on properties such as zeta potential and average particle size. The additions were as follows: (1) addition of both nanoparticles and SDBS simultaneously in $100 \mathrm{ml}$ of DI water and placed under ultrasonication, (2) dissolution of SDBS in DI water followed by addition of nanoparticles and placed under ultrasonication, (3) dispersion of nanoparticles using ultrasonication in DI water followed by dissolution of SDBS. The analysis of average particle size and zeta potential deduced that addition methods 1 and 2 did not showcase a noticeable effect on these parameters. Method 3 analysis showcased a substantial increase in the average size of nanoparticles, a phenomenon that is undesirable. Therefore, method 1 was chosen as the most suitable one to prepare all nanofluids with SDBS in this study. Furthermore, 0.050.15 wt.\% SDBS dosage was chosen and used in this study for 0.05 wt. $\% \mathrm{Al}_{2} \mathrm{O}_{3}$ nanofluid samples.

\subsubsection{Particle size distribution (PSD) and zeta potential measurement}

The PSD and zeta potential of the dispersed $\mathrm{Al}_{2} \mathrm{O}_{3}$ nanoparticles in the prepared nanofluid samples were analyzed at $25^{\circ} \mathrm{C}$ using a Zetasizer Nano ZS (Malvern Instruments Ltd, Malvern, UK). This instrument measures the zeta potential using the Laser based technique and the average particle size using the Dynamic Light Scattering (DLS) method. The measurements for the zeta potential and PSD were carried out using samples in a disposable folded capillary cell (DTS 1070) and the $2 \mathrm{~mm}$ square polystyrene cuvette (DTS 0012), respectively. The mode 
of measurement was set to automatic which included a minimum of 10 runs based on the polydispersity index of the sample.

To investigate the effect of $\mathrm{pH}$, fresh nanofluid samples were used, with their pristine $\mathrm{pH}$ of $\sim 6$ being adjusted to low (5 and 4) or high (7,8, 9 and 10) values using dilute $\mathrm{HNO}_{3}$ and $\mathrm{NaOH}$ prior to each zeta potential and particle size distribution measurement. For each new $\mathrm{pH}$ value, the sample was allowed to equilibrate for $5 \mathrm{~min}$ prior to data acquisition. A starter $3100 \mathrm{pH}$ metre (Ohaus Corporation, USA) was used to measure and monitor the $\mathrm{pH}$ of the prepared nanofluid samples.

\subsubsection{Measurement of thermal conductivity}

A KD2-Pro thermal analyzer (Decagon, USA) was employed to measure the thermal conductivity of the fresh and aged nanofluid samples. The analyzer was used in conjunction with a supplied KS-1 sensor which is designed primarily for liquid samples with low viscosity. The working principle of the KD-2 Pro is the line heat source method. The analyzer was calibrated using the supplied glycerin sample of known thermal conductivity before taking each measurement. The sensor was also wiped with a damp tissue after each measurement to ensure best practice. All measurements were carried out at constant ambient temperature of $25^{\circ} \mathrm{C}$.

\subsection{Hot water consumption pattern}

To evaluate the performance of the HPSWH system under real operational conditions, it was tested based on a domestic hot water consumption pattern in all cases. Figure 4 shows the domestic hot water consumption pattern of Perth residents which was extracted from the reports published by Water Corporation of Western Australia (Loh and Coghlan, 2003). It is worth noting that these data have been collected from 720 houses across the Perth metropolitan area. 


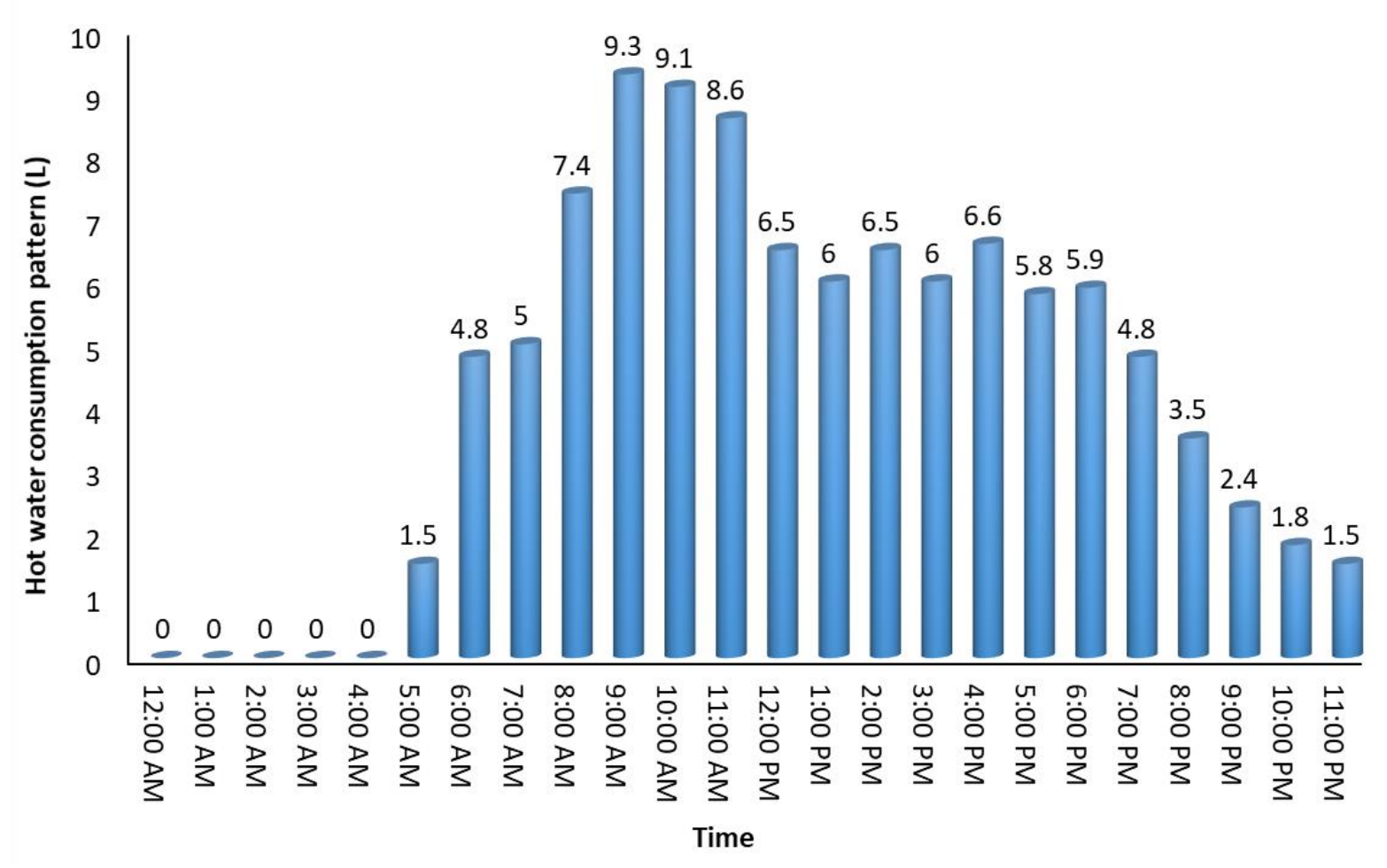

Fig. 4. The average hot water consumption pattern of Perth residents collected from 720 houses across the Perth metropolitan area by Water Corporation of Western Australia (Loh and Coghlan, 2003).

\subsection{Adjusting working fluid mass flow rate}

Figure 5 shows the solar working fluid pattern used in this study (Case III). It was regulated based on solar radiation starting from mass flow rate of $2 \mathrm{~L} / \mathrm{min}$ in the morning. It then increased as time moved towards the noon reaching the high values of $3.5 \mathrm{~L} / \mathrm{min}$ and $4 \mathrm{~L} / \mathrm{min}$ at 11:30 and 12:30, respectively. Afterwards, the mass flow rate started to decrease towards 2 $\mathrm{L} / \mathrm{min}$ as the solar radiation was decreasing. 


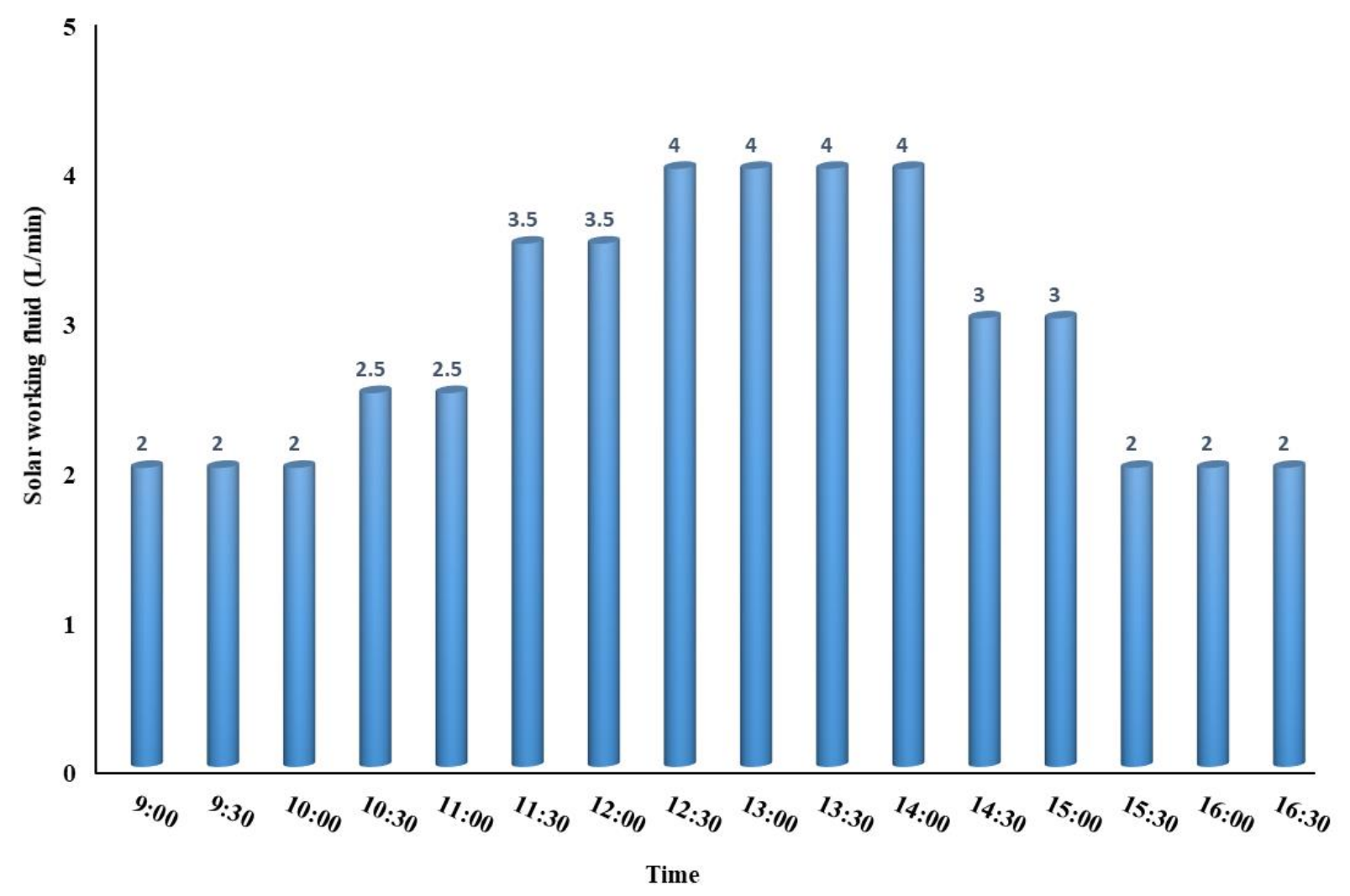

Fig. 5. Solar working fluid mass flow rate pattern

\subsection{Climatic conditions}

To have a reliable basis for comparison, the climatic conditions under which three cases were experimented should have been similar or close to each other. Therefore, based on weather forecast, three days in September 2018 (i.e. $21^{\text {st }}, 22^{\text {nd }}$, and $23^{\text {rd }}$ ) with similar climatic conditions were chosen for conducting the experiments. Figure 6 shows the solar radiation and ambient temperature during these three days. The solar radiation throughout all three days are almost similar. There is a sharp drop in solar radiation in third day which is due to the overcast sky occurred at around 13:30 and lasted for 10 minutes. The ambient temperature in three days are also close to each other with a few degrees divergence at specific times of the day. Taking this fact into account that the influence of solar radiation intensity on the thermal performance of 
heat pipe solar systems is more significant than ambient temperature, one can claim that all three experiments have been performed in almost similar climatic conditions.
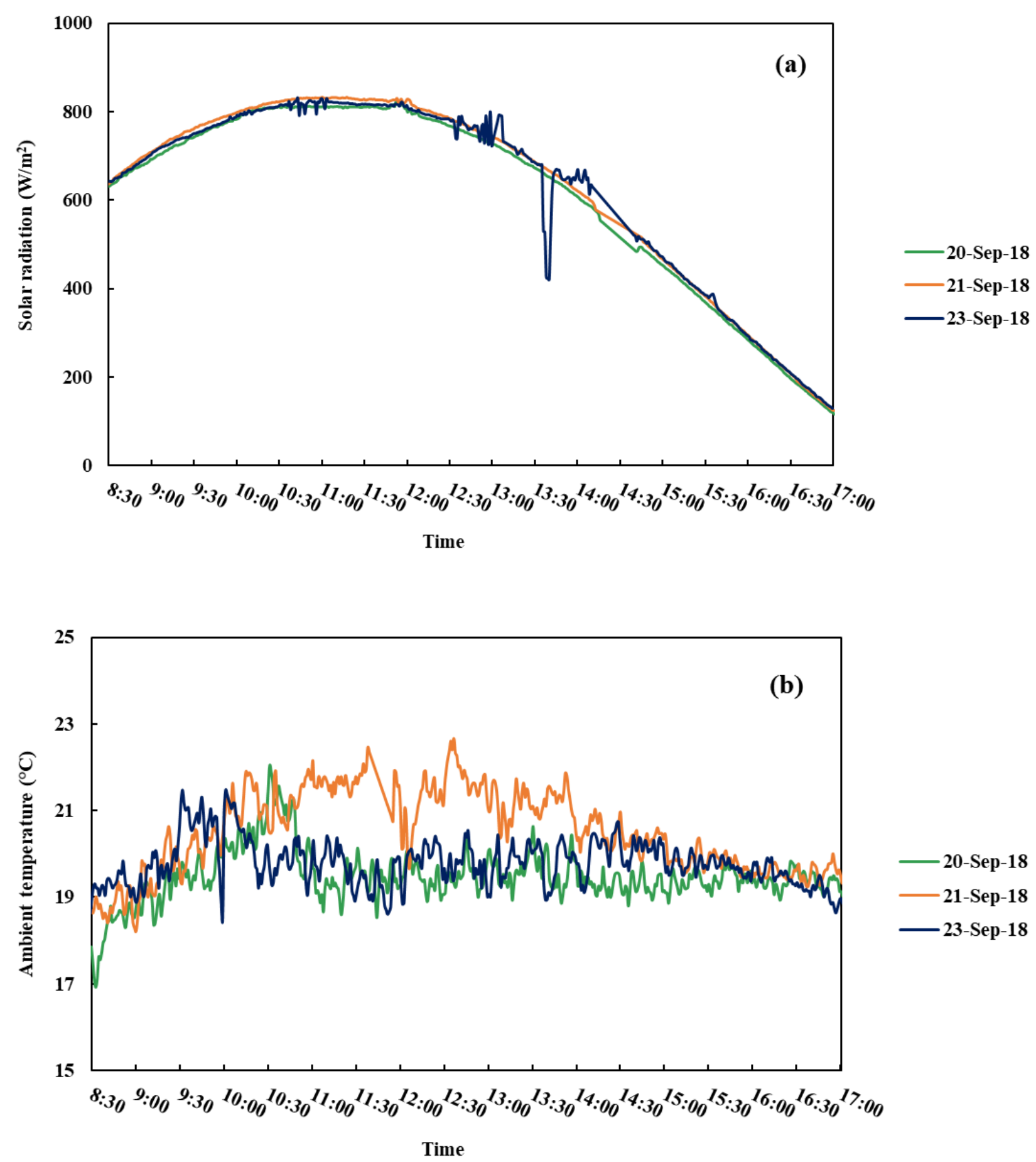

Fig. 6. Climatic conditions under which the experiments have been conducted: (a) solar radiation, and (b) ambient temperature 


\section{Governing equations}

\subsection{Energy and exergy efficiency}

The amount of transferred energy to the solar working fluid can be determined by (Azad, 2008):

$$
\mathrm{Q}_{a b}=m_{w f} C_{w f}\left(T_{w f, o-} T_{w f, i}\right)
$$

where $T_{w f, i}\left({ }^{\circ} \mathrm{C}\right)$ and $T_{w f, o}\left({ }^{\circ} \mathrm{C}\right)$ are inlet and outlet temperatures of the solar collector, respectively. In this equation, $m_{w f}(\mathrm{~kg} / \mathrm{s})$ and $C_{w f}(\mathrm{~J} / \mathrm{kgK})$ also represent the mass flow rate and heat capacity of the solar working fluid.

The thermal efficiency of the HPSC $\left(\eta_{c}\right)$ can be obtained from (Azad, 2008):

$$
\eta_{c}=\frac{Q_{a b}}{G A_{c}}
$$

where $\mathrm{G}\left(\mathrm{W} / \mathrm{m}^{2}\right)$ and $\mathrm{A}_{\mathrm{c}}\left(\mathrm{m}^{2}\right)$ represent solar radiation and area, respectively.

Besides thermal analysis, exergy analysis is a useful tool to investigate the significant energy losses in terms of time and magnitude. It is also useful to study the opportunities for thermodynamic enhancement of the solar system by determining the parameters affecting the system's thermodynamic imperfection and evaluating them quantitatively resulting in more efficient design of solar systems (Gunerhan and Hepbasli, 2007).

The exergy balance equation of the system can be written as (Akpinar and Koçyiğit, 2010):

$$
\sum E x_{\text {in }}-\sum E x_{\text {out }}=E x_{\text {dest }}
$$

where $E x_{\text {in }}(\mathrm{kW}), E x_{\text {out }}(\mathrm{kW})$ represent the inlet and outlet exergy rates of the control volume, respectively. $E x_{\text {dest }}(\mathrm{kW})$ in this equation is the exergy rate destroyed in the control volume.

Equation 3 can be expanded to the following equation (Daghigh, R. and Shafieian, A., 2016a): 


$$
\sum\left(1-\frac{T_{o}}{T_{k}}\right) Q_{k}-W+\sum m_{\text {in }} \varphi_{\text {in }}-\sum m_{\text {out }} \varphi_{\text {out }}=E x_{\text {dest }}
$$

where $Q(\mathrm{~kW})$ and $W(\mathrm{~kW})$ represent heat transfer and work rate, respectively. In this equation, $\mathrm{T}_{0}\left({ }^{\circ} \mathrm{C}\right), \mathrm{T}_{\mathrm{k}}\left({ }^{\circ} \mathrm{C}\right), \mathrm{m}_{\mathrm{in}}(\mathrm{kg} / \mathrm{s})$, and $\mathrm{m}_{\text {out }}(\mathrm{kg} / \mathrm{s})$ represent the dead state temperature, temperature at a specific location, inlet and outlet mass flow rates, respectively. In equation $4, \varphi(\mathrm{kJ} / \mathrm{kg})$, is the physical exergy flow which can be determine by (Daghigh, R. and Shafieian, A., 2016c):

$$
\varphi_{\text {in } / \text { out }}=\left(h_{\text {in/out }}-h_{0}\right)-T_{0}\left(s_{\text {in/out }}-s_{0}\right)
$$

where $h(\mathrm{~kJ} / \mathrm{kg})$ and $s(\mathrm{~kJ} / \mathrm{kgK})$ represent specific enthalpy and entropy, respectively. $T_{0}(\mathrm{~K})$ is the temperature at dead state and subscripts 'in' and 'out' stand for inlet and outlet, respectively. Exergy efficiency of the solar system can be written as (Daghigh, R. and Shafieian, A., 2016d):

$$
\eta_{s c}=\frac{E x_{u}}{E x_{s c}}
$$

where $E x_{u}(\mathrm{~kW})$ and $E x_{s c}(\mathrm{~kW})$ are the useful delivered and the collector absorbed exergy, respectively, and can be determined by (Daghigh, R. and Shafieian, A., 2016b):

$$
\begin{aligned}
& E x_{u}=m_{w}\left[\left(h-h_{0}\right)-T_{0}\left(s-s_{0}\right)\right] \\
& E x_{u}=m_{w} C_{w}\left[\left(T_{o}-T_{i}\right)-T_{0}\left(\ln \frac{T_{o}}{T_{i}}\right)\right] \\
& E x_{s c}=A G\left[1+\frac{1}{3}\left(\frac{T_{o}}{T_{s r}}\right)^{4}-\frac{4}{3}\left(\frac{T_{o}}{T_{s r}}\right)\right]
\end{aligned}
$$

where $T_{s r}(\mathrm{~K})$ represents the solar radiation temperature and its quantitative value is $6000 \mathrm{~K}$.

The thermo-physical properties of the nanofluid such as heat capacity was calculated using the equations provided in the literature (Pak and Cho, 1998; Xuan and Roetzel, 2000; Zhou). 


\subsection{Uncertainty analysis}

Uncertainty analysis is a useful tool to determine the calculated and measured uncertainties.

The measured parameters uncertainty consists of systematic errors, including data acquisition, calibration, and equipment accuracy, and random errors. The standard deviation method was applied to determine the total uncertainty (Moffat, 1988):

$$
W_{t}=\sqrt{\varepsilon_{s}^{2}+\varepsilon_{r}^{2}}
$$

where $W_{t}, \varepsilon_{s}$, and $\varepsilon_{\mathrm{r}}$ represent total uncertainty, systematic errors, and random errors, respectively. Following equations can be used to determine the systematic and random errors (Moffat, 1988):

$$
\begin{gathered}
\varepsilon_{s}=\sqrt{\sum_{i=1}^{n} \varepsilon_{s, i}^{2}} \\
\varepsilon_{r}=\sqrt{\sum_{i=1}^{n} \varepsilon_{r, i}^{2}}
\end{gathered}
$$

The parameter $n$ in abovementioned equations represents the number of error sources and $\varepsilon_{r, i}$ can be determine by (Moffat, 1988):

$$
\varepsilon_{r, i}=\sqrt{\frac{\sum_{i=1}^{n}\left(\varphi_{i}-\bar{\varphi}\right)^{2}}{N(N-1)}}
$$

where $N$ represents the number of measurement repetitions and $\bar{\varphi}$ is the average value of the measurements.

Based on the propagation of errors method (Holman, 2011), the uncertainty of the calculated parameters $\left(W_{R}\right)$ can be calculated from: 
$W_{R}=\sqrt{\sum_{i=1}^{n}\left(\frac{\partial R}{\partial x_{i}} W_{i}\right)^{2}}$

where $\mathrm{R}=\mathrm{R}\left(\mathrm{a}_{1}, \mathrm{a}_{2}, \ldots, \mathrm{a}_{\mathrm{n}}\right), \mathrm{a}_{\mathrm{n}}$ is an independent variable and $W$ is its uncertainty, respectively.

Table 3 depicts the uncertainties of measured and calculated parameters in this study.

Table 3. Uncertainty analysis of measured and calculated parameters.

\begin{tabular}{|c|c|c|c|c|c|}
\hline Parameter & Instrument & $\begin{array}{l}\text { Operation } \\
\text { range }\end{array}$ & $\begin{array}{l}\text { Systematic } \\
\text { error }( \pm \%)\end{array}$ & $\begin{array}{c}\text { Random } \\
\text { error }( \pm \%)\end{array}$ & $\begin{array}{c}\text { Total Uncertainty } \\
( \pm \%)\end{array}$ \\
\hline $\begin{array}{c}\text { Solar } \\
\text { radiation }\end{array}$ & Pyranometer & $0-2000 \mathrm{~W} / \mathrm{m}^{2}$ & 3 & 0 & \pm 3 \\
\hline $\begin{array}{c}\text { Wind } \\
\text { velocity }\end{array}$ & $\begin{array}{l}\text { Wind speed } \\
\text { sensor }\end{array}$ & $0-75 \mathrm{~m} / \mathrm{s}$ & 2.6 & 0 & \pm 2.6 \\
\hline $\begin{array}{c}\text { Ambient } \\
\text { temperature }\end{array}$ & $\begin{array}{c}\text { Air } \\
\text { temperature } \\
\text { sensor }\end{array}$ & $-20-60^{\circ} \mathrm{C}$ & 1 & 0 & \pm 1 \\
\hline Flow rate & Flow meter & $0-0.068 \mathrm{~kg} / \mathrm{s}$ & 1.34 & 0.45 & \pm 2 \\
\hline Temperature & Thermocouple & $-185-300{ }^{\circ} \mathrm{C}$ & 1.42 & 0.32 & \pm 1.7 \\
\hline $\begin{array}{l}\text { Thermal } \\
\text { efficiency }\end{array}$ & - & - & - & - & \pm 4.7 \\
\hline $\begin{array}{l}\text { Exergy } \\
\text { efficiency }\end{array}$ & - & - & - & - & \pm 3.8 \\
\hline
\end{tabular}

\section{Results and discussions}

The first part of this section (section 4.1) is allocated to the experiments conducted to find the optimum concentration and characteristics of the nanofluid which was supposed to act as the solar working fluid in Cases II and III. This section includes investigations about nanofluid stability and thermal conductivity. The results of additional investigations regarding the effects 
of aging on average particle size and thermal conductivity are presented in Appendix A (sections A.1 and A.2). The next sections (sections 4.2-4.4) represent the results of the experiments conducted to study the effectiveness of the variable mass flow rate technique to improve the performance of HPSWH systems by running the system under similar climatic conditions and under a real residential hot water load at three different cases. These sections include thermal analysis (i.e. the amount of energy transferred to the solar working fluid and temperature difference between the collector inlet and outlet temperatures), efficiency analysis (i.e. the thermal efficiency of the system), and exergy analysis (i.e. energy loss and system's thermodynamic imperfections).

\subsection{Nanofluid optimum concentration, stability and thermo-physical properties investigations}

\subsubsection{Nanofluid stability}

$\mathrm{Al}_{2} \mathrm{O}_{3} / \mathrm{DI}$ water nanofluids (0.05 wt.\%) without addition of SDBS along with nanofluid prepared with varying SDBS concentrations were analysed for the zeta potential values. The zeta potential magnitude is a good indicator of the stability of the nanofluid such that values obtained outside the range of $+30 \mathrm{mV}$ to $-30 \mathrm{mV}$ correspond to a stable nanofluid. Also, it is worth noting that the higher the magnitude of zeta potential, the greater the electrostatic repulsion of the suspended nanoparticles, therefore the greater the stability of the nanofluid. The value of $\mathrm{pH}$ has a significant effect on the zeta potential value as it dictates the electrostatic repulsion between the particles such that if the particle in a suspension has a negative zeta potential and more acid is added to it, then there will be a point at which the charges are neutralised, and the zeta potential will be zero. The results presented in Fig. 7 showed that the nanofluid without any SDBS added to it was affected by the $\mathrm{pH}$ as the zeta potential value dropped from a positive value to a negative value as the $\mathrm{pH}$ increased. The zeta potential was 
observed to be zero at the isoelectric point (IEP) between $\mathrm{pH} 8$ and 9 which corresponds to the least stable nanofluid. Addition of SDBS in varying concentration had a significant effect on the zeta potential values, such that the effect of $\mathrm{pH}$ observed previously was nullified and the nanofluid also exhibited only negative zeta potential values, this implied that the use of SDBS enabled the fabrication of stable $\mathrm{Al}_{2} \mathrm{O}_{3} / \mathrm{DI}$ water nanofluids at any $\mathrm{pH}$ value. The negative zeta potential values could be attributed to the SDBS dissociating in the DI water to produce phenyl sulfonic groups which were absorbed on to the nanoparticles. The variation in concentration of SDBS also affected the zeta potential values as the highest concentration of $0.15 \mathrm{wt} . \%$ resulted in the highest zeta potential values obtained. The addition of $0.1 \mathrm{wt} . \%$ and 0.05 wt. $\%$ SDBS had a similar effect albeit the effect of $0.05 \mathrm{wt} . \%$ was not as pronounced as that of $0.15 \mathrm{wt} . \%$ and $0.1 \mathrm{wt} . \%$. However, zeta potential on its own could not be a determining factor to decide the optimum fabrication technique and concentration of the SDBS as thermal conductivity also plays a vital role. Although it was predicted that with the increased stability, a substantial increase in the thermal conductivity was expected, it required further investigation to ensure that the nanofluid fabricated did not compromise the thermal conductivity on the expense of the stability. 


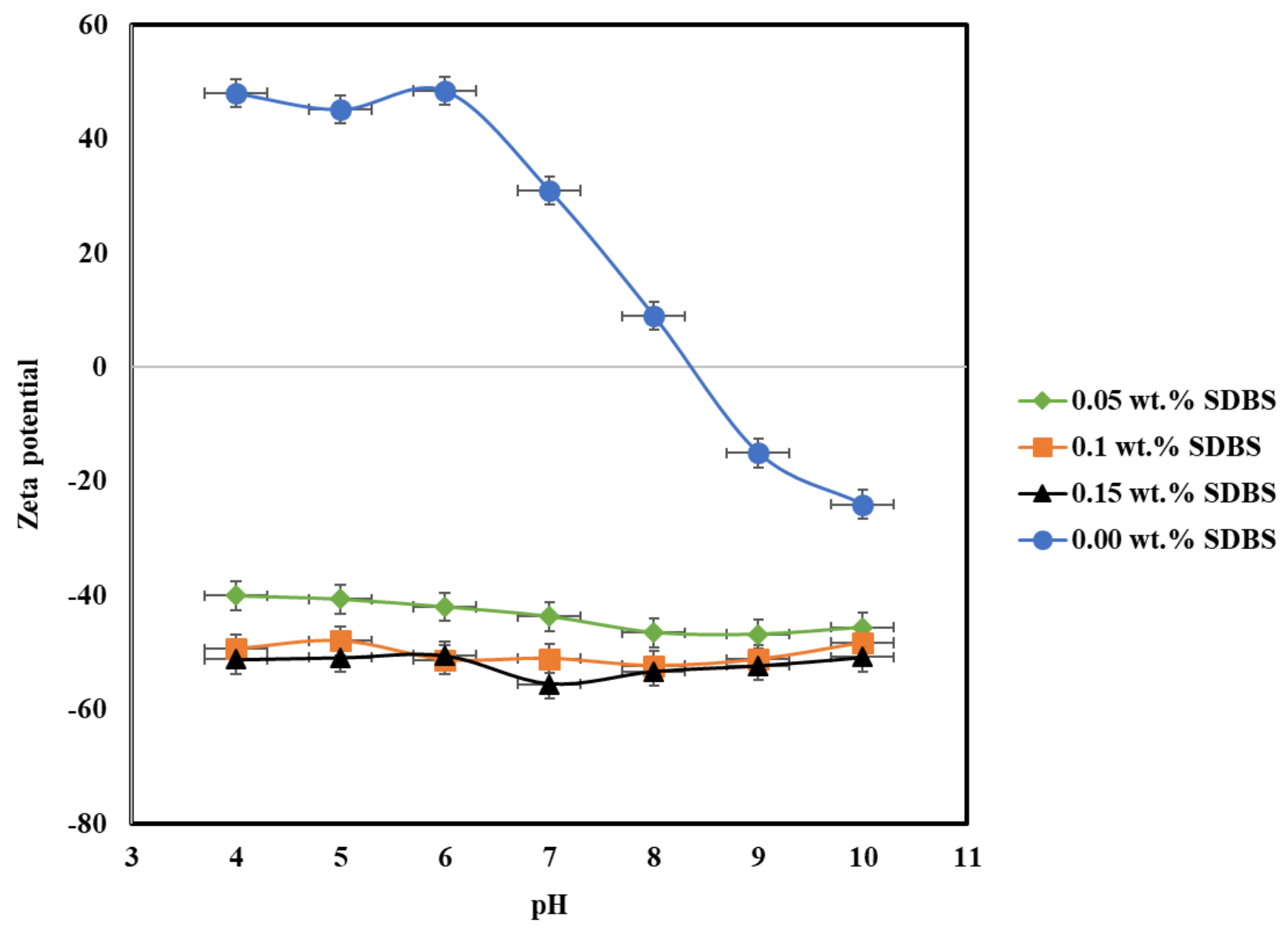

Fig. 7. Effect of $\mathrm{pH}$ with varying SDBS concentrations on the Zeta potential of $0.05 \mathrm{wt} . \%$

\section{$\mathrm{Al}_{2} \mathrm{O}_{3} / \mathrm{DI}$ water nanofluid}

\subsubsection{Optimum thermal conductivity of Nanofluid}

Figure 8 shows the thermal conductivity of the fabricated $\mathrm{Al}_{2} \mathrm{O}_{3} / \mathrm{DI}$ water nanofluid at varying $\mathrm{pH}$ values. It is evident that SDBS concentration had an important role in determining the extent of thermal conductivity enhancement observed. Due to the increased stability observed at higher concentrations, it was expected that increased SDBS concentration would relate to greater thermal conductivity enhancement. However, it is evident that at a higher concentration of 0.15 wt. $\%$, the thermal conductivity enhancement was the poorest. This result was contradictory to the zeta potential values showed in Fig. 7 and therefore reiterated the need to further investigate the thermal conductivity enhancement of the nanofluid and to deter solely 
the use of zeta potential values as an approach to fabricating a nanofluid. It was prudent to ensure that in order to utilise the nanofluids, stability and the thermal conductivity would both be vital factors and one would not have precedence over the other. The observation of poor thermal conductivity enhancement at $0.15 \mathrm{wt} . \%$ could be attributed to the narrowing of the available heat transfer area. The surplus of SDBS particles hinder the heat transfer due to their poor thermal conductivity therefore affecting the nanofluid's thermal property. Bearing in mind the average particle size, zeta potential and thermal conductivity, $0.1 \mathrm{wt} . \%$ SDBS was regarded as the optimum concentration of SDBS for $0.05 \mathrm{wt} \% \mathrm{Al}_{2} \mathrm{O}_{3} / \mathrm{DI}$ water nanofluid at which it exhibited the highest stability and thermal conductivity enhancement.

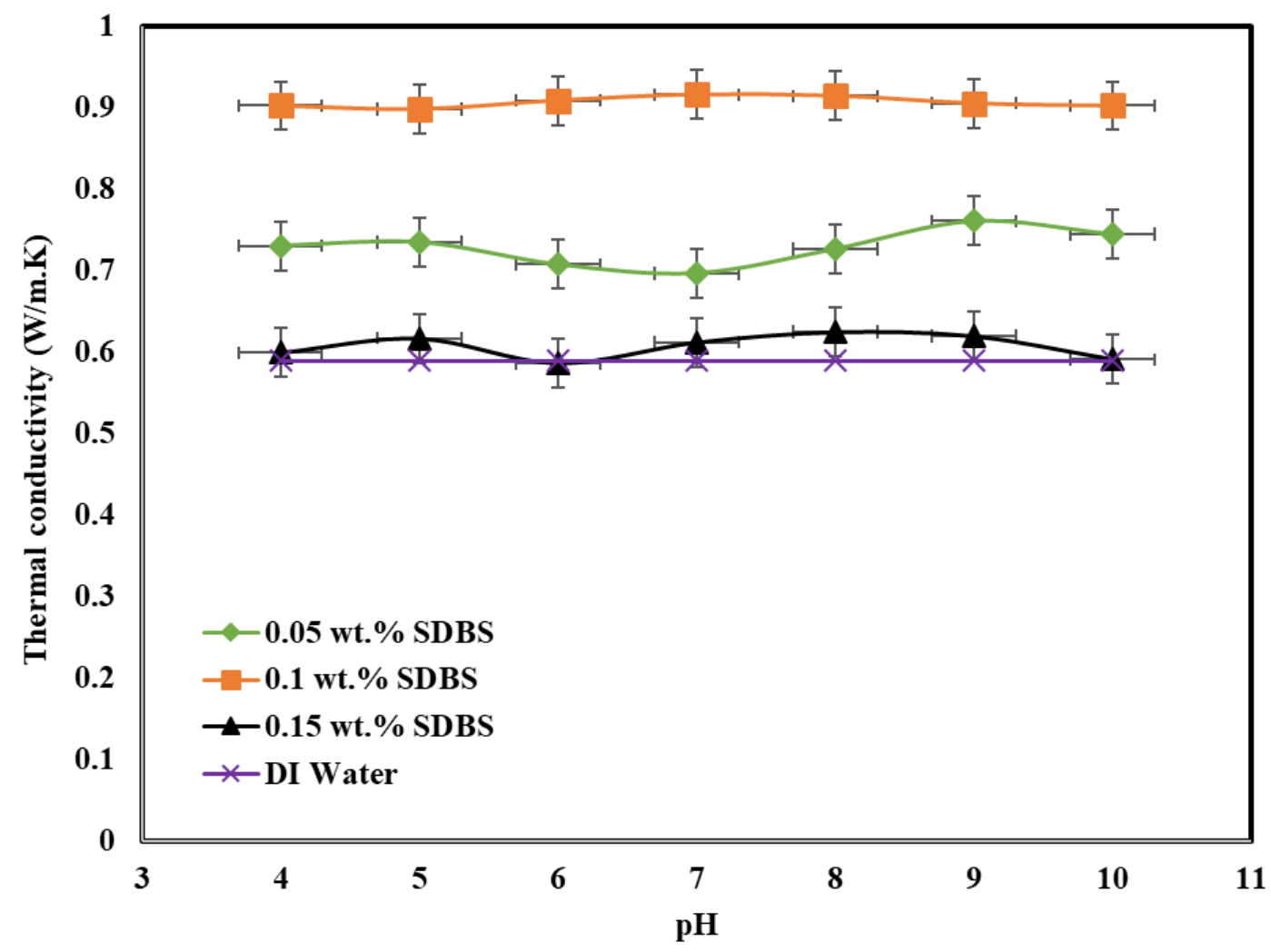

Fig. 8. Thermal conductivity of $\mathrm{Al}_{2} \mathrm{O}_{3} / \mathrm{DI}$ water at varying $\mathrm{pH}$ values as a function of different SDBS concentrations at $25^{\circ} \mathrm{C}$. 


\subsection{Thermal analysis}

Figures $9 \mathrm{a}$ and $9 \mathrm{~b}$ show the amount of energy transferred to the solar working fluid and temperature difference between the collector inlet and outlet temperatures in Cases I, II, and III throughout the day. Based on the results, using the optimized nanofluid at a constant mass flow rate (Case II) increased the transferred energy to the solar working fluid compared with using distilled water at the same mass flow rate (Case I), and moreover, implementing the variable mass flow rate technique (Case III) outperformed both of them resulting in a significant improvement in the performance of the HPSWH system. For example, by considering the average amount of the transferred energy improvement and compared with Case I, the transferred energy to the solar working fluid in the HPSWH system increased by $8.9 \%$ in Case II and by $22.7 \%$ in Case III.

At the beginning of the day while the solar radiation was low, Case III with lower mass flow rate $(2 \mathrm{~L} / \mathrm{min}$ ) outperformed Cases I and II both with mass flow rates of $3 \mathrm{~L} / \mathrm{min}$. For instance, the amount of transferred energy at 9:45 AM in Cases I, II, and III were 890, 965, and 1136 W, respectively. As timed passed and solar radiation increased, solar working fluid mass flow rate increase leaded to higher amounts of transferred energy in Case III. As time moved towards afternoon and by decreasing the mass flow rate, all cases reached almost the same mass flow rate and the amounts of transferred energy got closer.

It can also be observed that the overall trend of the transferred energy followed the same trend as solar radiation in all cases. However, fluctuations can be seen in the graphs which are mainly due to hot water extraction based on hot water consumption pattern in all cases. As hot water was extracted from the storage tank to simulate the real residential consumption, tap water entered the bottom section of the tank (near the location of the copper coil) to replace the consumed water. As a result, the temperature difference and heat transfer rate between the water inside the storage tank and the solar working fluid inside the coil increased, and hence, 
the copper coil outlet temperature (collector inlet temperature) decreased. Consequently, the temperature difference between solar working fluid and heat pipe condensers increased leaded to higher heat transfer inside the manifold. This resulted in higher temperature difference between the collector inlet and outlet temperatures and also higher amounts of transferred energy which obviously explains the fluctuations in graphs at the times of water extraction.

By passage of time and occurrence of continuous heat transfer inside the tank, the temperature of the water inside it increased leading to lower heat transfer rate through the coil, and consequently, the copper coil outlet temperature and temperature difference between the collector inlet and outlet temperatures decreased. The results indicate that besides the positive effect of having a consumption pattern on the performance of the solar systems, considering it is essential to acquire a comprehensive understanding of HPSWH systems.

In addition, and compared with other cases, there are extra fluctuations in Case III which are mainly due to the solar working fluid mass flow rate changes. Increasing the mass flow rate because of solar radiation increase had a positive effect on the transferred energy but decreased the outlet temperature of the collector. For instance, the transferred energy at 11:30 AM was around $1000 \mathrm{~W}$ which increased sharply to around $1210 \mathrm{~W}$ as the solar working mass flow rate changed. This is because the potential of the system was higher at larger values of solar radiation and higher mass flow rate leads to taking advantage of this potential more efficiently. On the other hand, the mass flow rate and collector outlet temperature are oppositely related which explains the lower values of temperature difference at the midday period with high mass flow rates. 

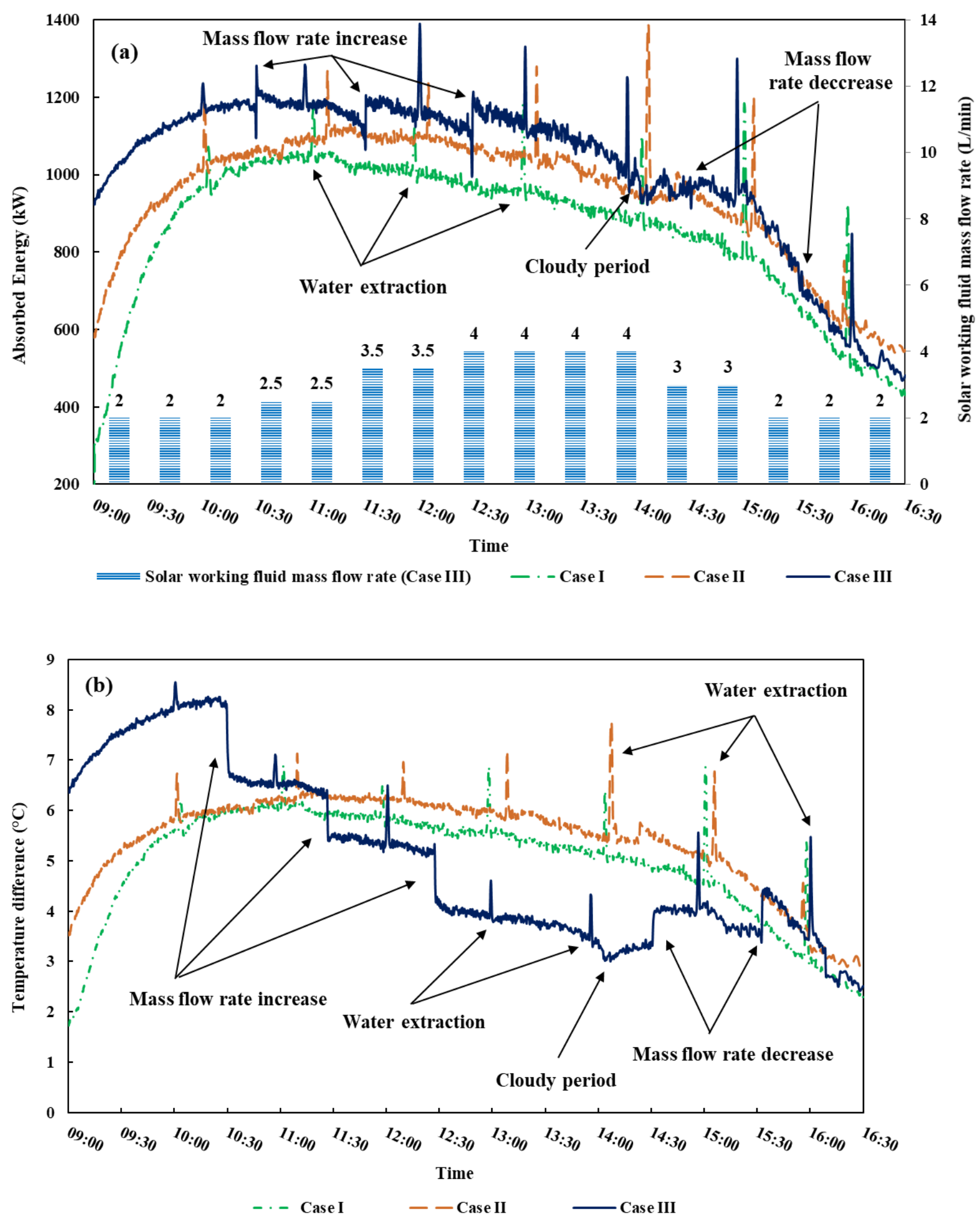

Fig. 9. (a) The amount of transferred energy to the solar working fluid, and (b) temperature difference between the collector inlet and outlet temperatures 


\subsection{Efficiency analysis}

Figure 10 depicts the thermal efficiency of the HPSC as a function of time in all three cases throughout the day. These results revealed that using the proposed optimized nanofluid at a constant mass flow rate (Case II) enhanced the thermal efficiency of the system compared with using distilled water at the same mass flow rate (Case I). Moreover, implementing the variable mass flow rate technique (Case III) outperformed both Cases I and Case II resulting in a significant improvement in the performance of the HPSWH system. For instance, at 11:30 AM and 13:30 PM, the thermal efficiencies in Case III were $74.2 \%$ and $84.5 \%$, respectively. At the same times, the thermal efficiencies in Case II were respectively $59.2 \%$ and $67.9 \%$ while they were $52.5 \%$ and $51 \%$ in Case I. The main reason for the advantage of using nanofluid (in cases II and III) over distilled water (Case I) is the presence of nanoparticles and their positive consequent effect on the thermal conductivity and heat transfer rate improvement of the solar working fluid. In addition, nanoparticles increase the heat transfer surface area resulting in noticeable improvement in the heat capacity and heat transfer rate of the solar working fluid.

In all three cases, the lowest thermal efficiency occurred at the beginning of the day because of low solar radiation and at the same time low solar working fluid temperature. The thermal efficiency increased by the passage of time and having higher solar radiation. The fluctuations in all the graphs are attributed to solar working fluid mass flow rate changes and also hot water extraction which both increased the overall efficiency of the system. As explained earlier, tap water injection to compensate the extracted hot water decreased the collector inlet temperature resulting in higher amounts of transferred energy to the solar working fluid and consequently higher thermal efficiencies.

Analyzing the results showed the significant positive effect of the variable mass flow rate technique on the overall performance of the system. For example, changing the mass flow rate at 10:30 AM and 12:30 PM increased the thermal efficiency from $63 \%$ and $66 \%$ to $81 \%$ and 
$81.9 \%$, respectively. Taking the average amount of efficiency improvement into account, the thermal efficiency of the HPSWH system increased by $12.46 \%$ in Case II and by $19.34 \%$ in Case III compared with Case I. Overall, the results suggest that making a prudent selection of solar working fluid and regulating its mass flow rate based on the solar radiation can lead HPSWH systems towards their optimum performance.

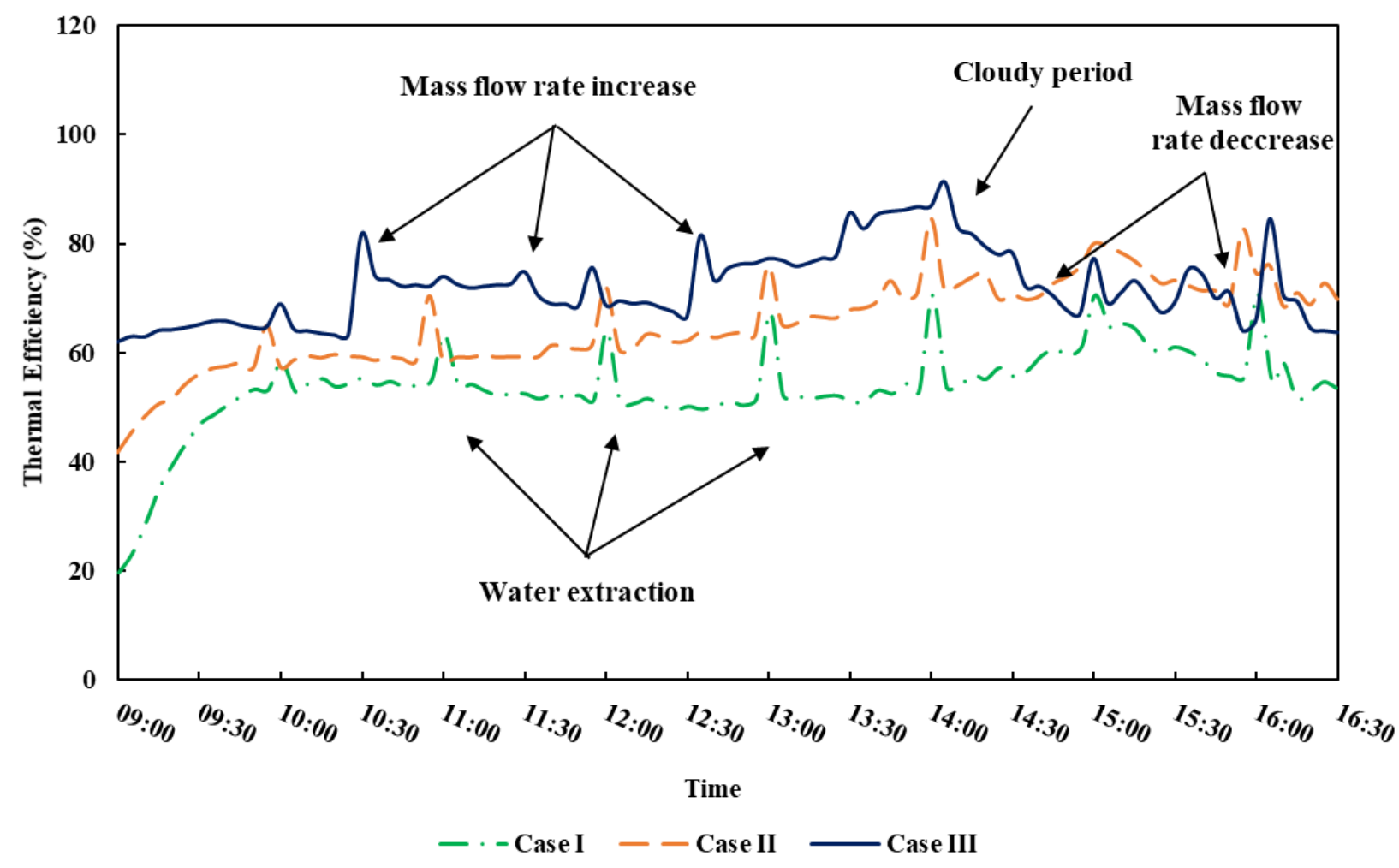

Fig. 10. The thermal efficiency of the HPSC as a function of time

\subsection{Exergy analysis}

Figure 11 indicates the exergy efficiency of the HPSC as a function of time in all three cases throughout the day. The graphs revealed that the overall changes in the exergy efficiency of the system was ascending with time with the highest exergy destruction occurring at the beginning of the day. In addition, the system had lower exergy destruction (higher exergy efficiency) when it was operated with a variable mass flow rate technique (Case III) followed by when it was operated with the nanofluid at a constant mass flow rate (Case II) and with 
distilled water at a constant mass flow rate (Case I). Therefore, by considering the average amount of exergy efficiency improvement and compared with Case I, the exergy efficiency of the HPSWH system increased by $1.58 \%$ in Case II and by $2.66 \%$ in Case III.

Moreover, the results indicated that both changing the solar working fluid mass flow rate and hot water extraction decreased the exergy destruction of the system. This is because the temperature difference between the collector inlet and outlet increased by extracting hot water from the storage tank resulting in higher transferred energy and exergy efficiencies. In addition, although increasing the solar working fluid mass flow rate decreased the temperature difference between collector inlet and outlet which in return increased exergy destruction, it increased the transferred energy to the solar working fluid leading to lower exergy destruction. Hence, the overall effect of changing the solar working fluid mass flow rate on exergy efficiency of the HPSWH system was positive.

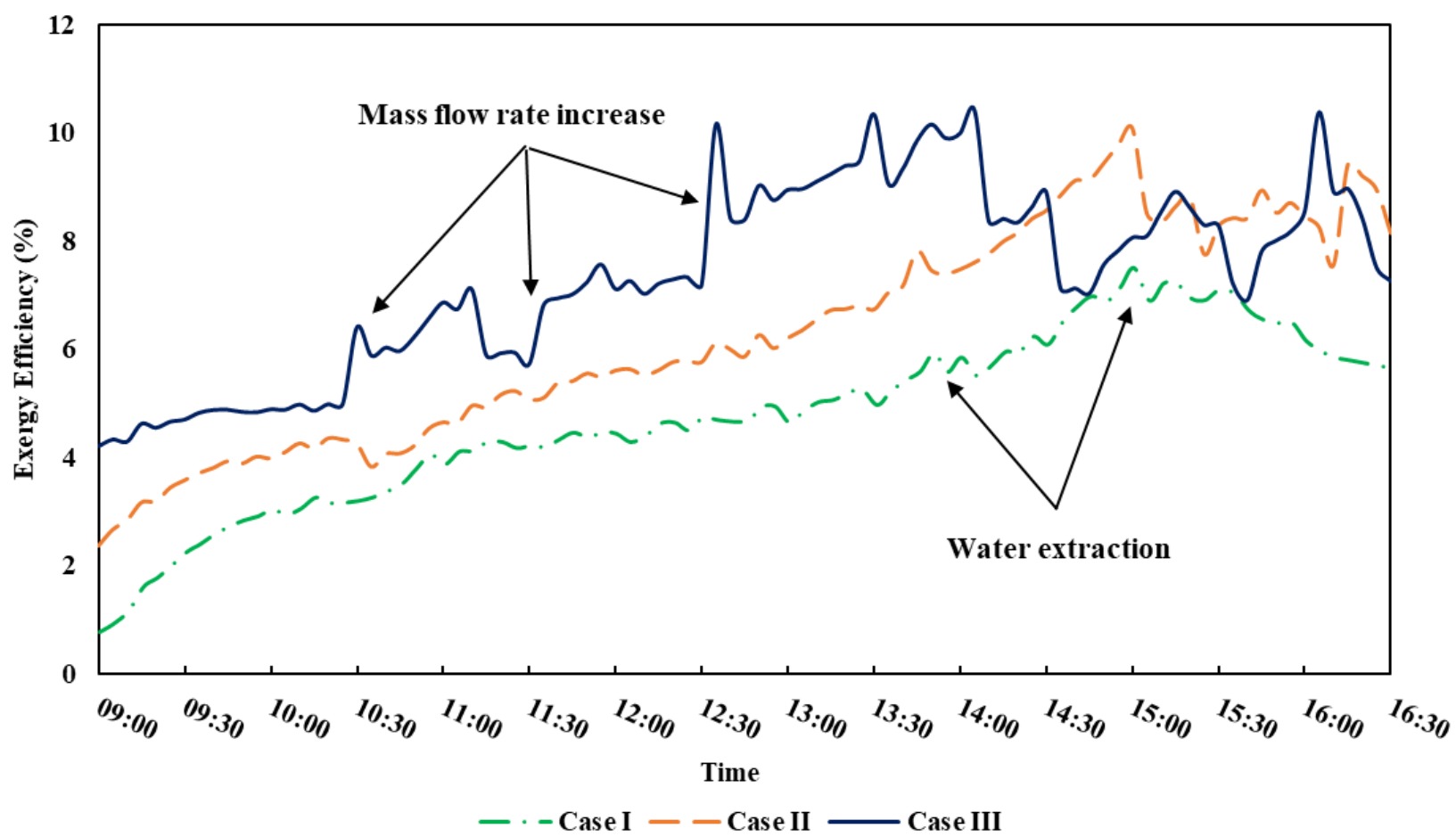

Fig. 11. The exergy efficiency of the HPSC as a function of time 


\section{Conclusions}

This study aimed to enhance the overall performance of HPSWH systems by regulating the solar working fluid mass flow rate with the solar radiation intensity. First, an $\mathrm{Al}_{2} \mathrm{O}_{3}$-DI water nanofluid was fabricated, optimized, and checked for its stability. Then, the HPSWH system was tested under similar climatic conditions using distilled water at constant mass flow rate (Case I), the optimized nanofluid at constant mass flow rate (Case II), and the optimized nanofluid at variable mass flow rate (Case III). The following results were obtained:

- Using the optimized nanofluid as the solar working fluid enhanced the performance of the HPSWH system. In this study, Sodium Dodecyl BenzeneSulfonate (SDBS) at 0.1 wt.\% was the optimum concentration of SDBS for 0.05 wt. $\% \mathrm{Al}_{2} \mathrm{O}_{3} / \mathrm{DI}$ water nanofluid exhibiting the highest stability and thermal conductivity enhancement.

- The highest thermal efficiency improvement of the system occurred when nanofluid with variable mass flow rate was used (Case III by 19.34\%) followed by use of distilled water with variable mass flow rate (Case II by $12.46 \%$ ).

- Exergy efficiency improvement of Case III was $2.66 \%$ followed by $1.58 \%$ in Case II.

- The transferred energy to the solar working fluid in the system increased by $8.9 \%$ in Case II and by $22.7 \%$ in Case III compared with Case I.

- The application of variable mass flow rate significantly improved the overall performance of the HPSWH system.

- Further studies regarding the detailed regulation/optimization of the solar working fluid mass flow rate with solar radiation intensity is recommended for future research. 


\section{Appendix A}

\section{A.1. Effect of aging on average particle size}

In order to analyse the effect of aging on the average particle size of $\mathrm{Al}_{2} \mathrm{O}_{3} / \mathrm{DI}$ water with 0.1 wt.\% SDBS, freshly prepared nanofluid samples were measured and stored. Measurements of the samples were conducted again after 24 hours, 48 hours and 120 hours. From the data presented in Figure 12, it can be observed that minimum aggregation was measured after 24 hours. After 48 hours, the average particle size increased significantly for samples at all $\mathrm{pH}$ values except $\mathrm{pH} 9$. After 120 hours, the average particle size was observed to increase further at all $\mathrm{pH}$ values except $\mathrm{pH} 7$ and 8, thereby indicating unpredictable aggregation pattern. From this analysis, it is noticeable that the aggregation trend of $\mathrm{Al}_{2} \mathrm{O}_{3} / \mathrm{DI}$ water nanofluids with 0.1 wt.\% SDBS does not adhere to a trend.

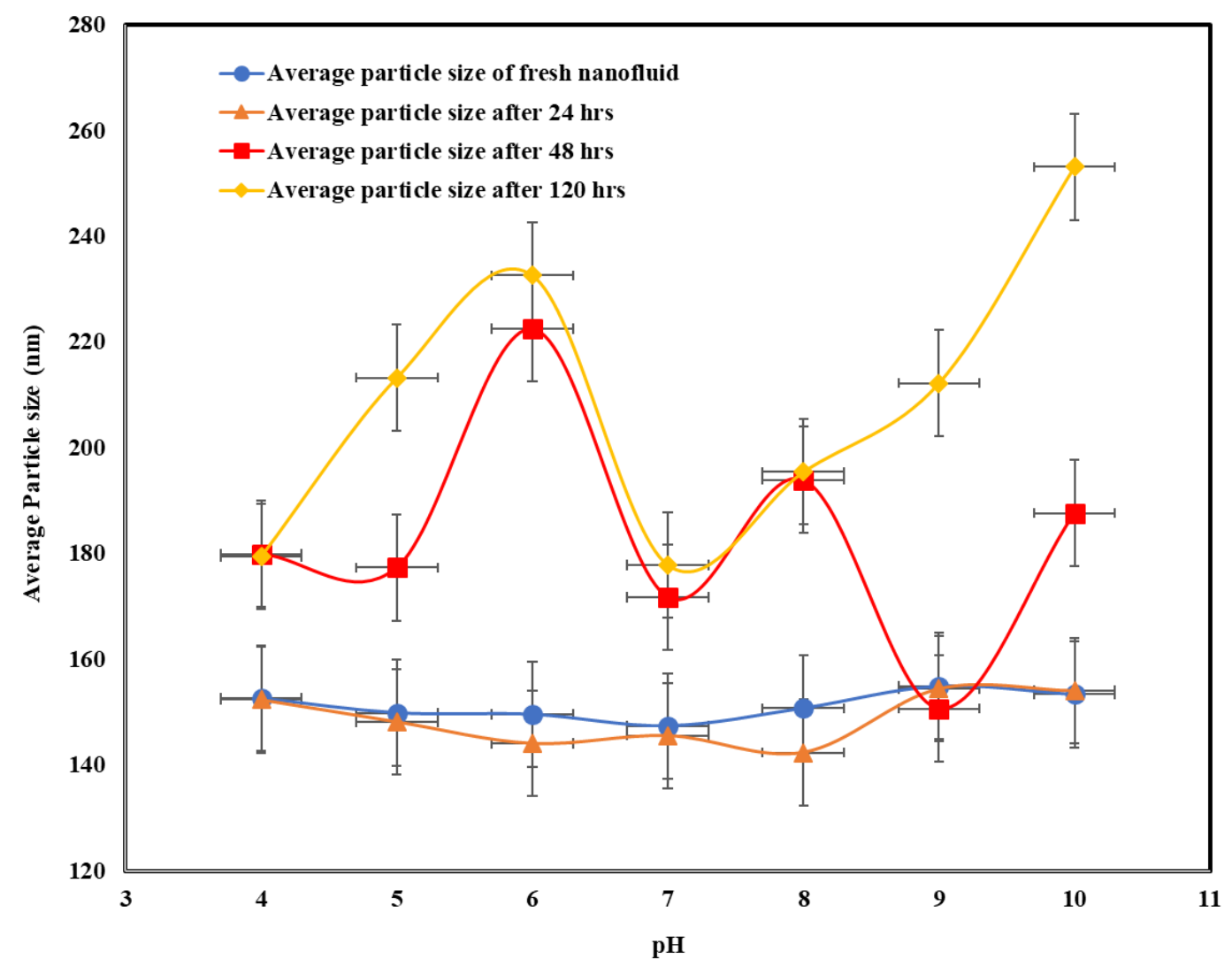

Fig. 12. Effect of aging time on the average particle size of 0.05 wt. $\% \mathrm{Al}_{2} \mathrm{O}_{3} / \mathrm{DI}$ water nanofluid with $0.1 \mathrm{wt} . \%$ SDBS 


\section{A.2. Effect of aging on thermal conductivity}

In order to analyse the effect of aging on the thermal conductivity of $\mathrm{Al}_{2} \mathrm{O}_{3} /$ DI water nanofluids, freshly prepared nanofluid samples were measured and stored. Measurements of the samples was conducted again after 24 hours, 48 hours and 120 hours.

From the data, it can be observed that freshly prepared $\mathrm{Al}_{2} \mathrm{O}_{3} /$ DI water nanofluid exhibits a significant enhancement in thermal conductivity for all $\mathrm{pH}$ values. The values are in accordance with the data for zeta potential and average particle size presented in Fig. 13. However, it is observed that the thermal conductivity of the $\mathrm{Al}_{2} \mathrm{O}_{3} /$ DI water drops significantly within 24 hours. This drop is largely experienced at $\mathrm{pH}$ values of 4,5 and 6. The matter of concern is that this significant drop is accompanied by minimal aggregation of particles. After 48 hours, the thermal conductivity values of the $\mathrm{Al}_{2} \mathrm{O}_{3} /$ DI water nanofluids continues to drop at all $\mathrm{pH}$ values. Furthermore, after 120 hours, the $\mathrm{Al}_{2} \mathrm{O}_{3} / \mathrm{DI}$ water nanofluids exhibits a further drop in thermal conductivity at $\mathrm{pH}$ values of 5,6 and 10. However, samples at other $\mathrm{pH}$ did not experience a significant drop after 120 hours, most notably $\mathrm{pH}$ 7,8 and 9. The significant drop in thermal conductivity in the absence of appreciable aggregation is an indication that other factors play a key role in the long term thermal stability of the $\mathrm{Al}_{2} \mathrm{O}_{3} / \mathrm{DI}$ water nanofluids, 


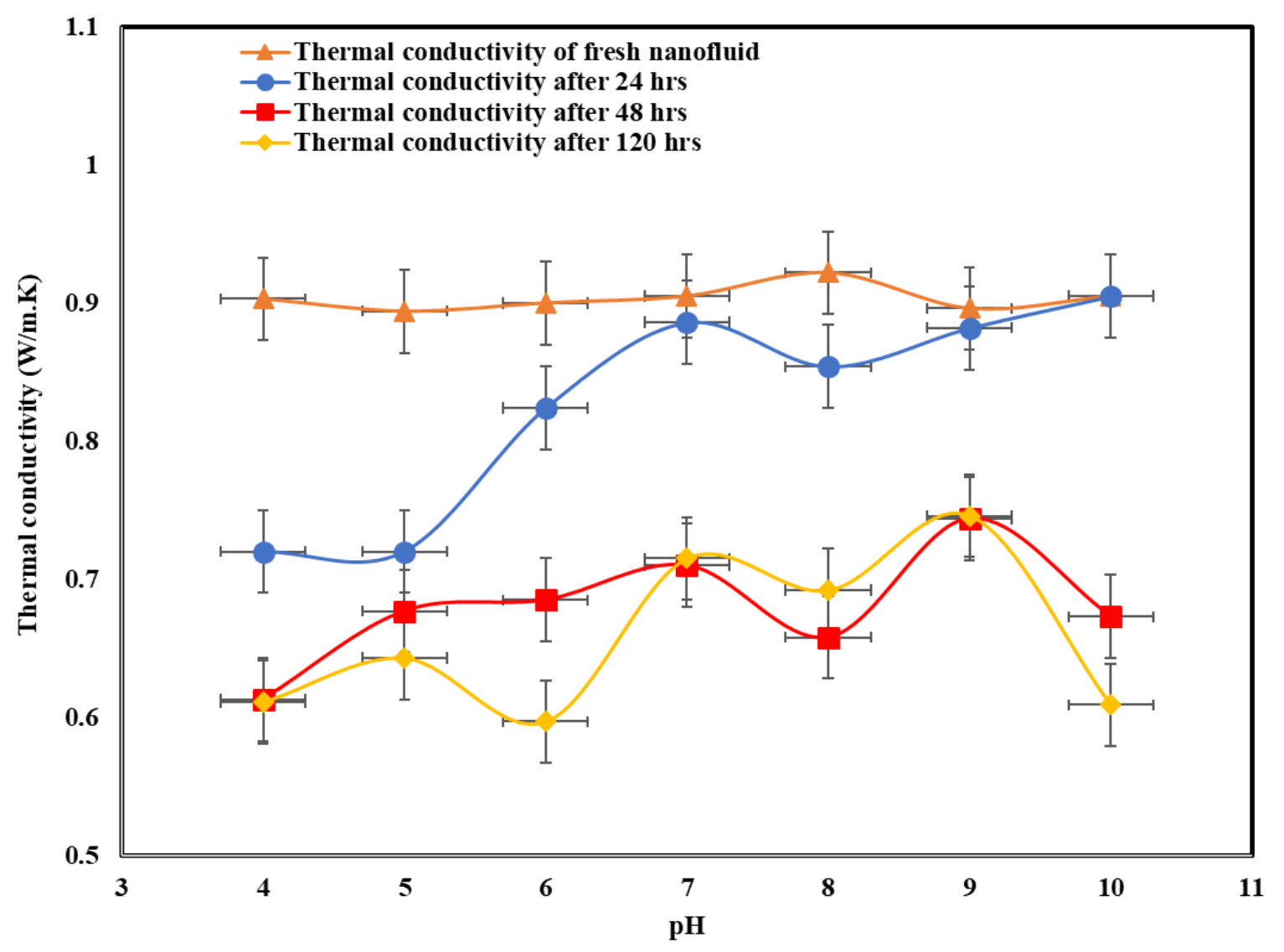

Fig. 13. Effect of aging time on the thermal conductivity of 0.05 wt.\% A12O3/DI water nanofluid with $0.1 \mathrm{wt} . \%$ SDBS at $25^{\circ} \mathrm{C}$. 


\section{References:}

Akpinar, E.K., Koçyiğit, F., 2010. Energy and exergy analysis of a new flat-plate solar air heater having different obstacles on absorber plates. Appl. Energy 87(11), 3438-3450.

Ali, N., Teixeira, J.A., Addali, A., 2018. A Review on Nanofluids: Fabrication, Stability, and Thermophysical Properties. J. Nanomater., 1-33.

Ayompe, L.M., Duffy, A., Keever, M.M., Conlon, M., McCormack, S.J., 2011. Comparative field performance study of flat plate and heat pipe evacuated tube collectors (ETCs) for domestic water heating systems in a temperate climate. Energy 36(5), 3370-3378.

Azad, E., 2008. Theoretical and experimental investigation of heat pipe solar collector. Exp. Therm. Fluid Sci. 32, 1666-1672.

Azad, E., 2018. Experimental analysis of thermal performance of solar collectors with different numbers of heat pipes versus a flowthrough solar collector. Renew. Sust. Energy Rev. 82, 4320-4325.

Chopra, K., Tyagi, V.V., Pandey, A.K., Sari, A., 2018. Global advancement on experimental and thermal analysis of evacuated tube collector with and without heat pipe systems and possible applications. Appl. Energy 228, 351-389.

Chopraa, K., Tyagia, V.V., Pandey, A.K., Sarid, A., 2018. Global advancement on experimental and thermal analysis of evacuated tube collector with and without heat pipe systems and possible applications. Appl. Energy 228 351-389.

Chougule, S., Sahu, S., Pise, A., 2013 Thermal performance of two phase thermosyphon on flat plate solar collectors using nanofluid. J. Sol. Energy Eng. 136 1-5.

Chow, T.-T., Bai, Y., Dong, Z., Fong, K.-F., 2013. Selection between single-phase and twophase evacuated-tube solar water heaters in different climate zones of China. Sol. Energy 98, 265-274.

Daghigh, R., Shafieian, A., 2016a. Energy-exergy analysis of a multipurpose evacuated tube heat pipe solar water heating-drying system. Experimental Thermal and Fluid Science 78, 266-277.

Daghigh, R., Shafieian, A., 2016b. Energy and exergy evaluation of an integrated solar heat pipe wall system for space heating. Sādhanā 41(8), 877-886.

Daghigh, R., Shafieian, A., 2016c. An experimental study of a heat pipe evacuated tube solar dryer with heat recovery system. Renewable energy 96, 872-880.

Daghigh, R., Shafieian, A., 2016. Theoretical and experimental analysis of thermal performance of a solar water heating system with evacuated tube heat pipe collector. Appl. Therm. Eng. 103, 1219-1227.

Daghigh, R., Shafieian, A., 2016d. Thermal Performance of a Double-Pass Solar Air Heater. Journal of Renewable Energy and Environment 3(2), 35.

Deng, Y., Quan, Z., Zhao, Y., Wang, L., Liu, Z., 2015. Experimental research on the performance of household-type photovoltaic-thermal system based on microheat-pipe array in Beijing. Energy Convers. Manag. 106, 1039-1347.

Deng, Y., Zhao, Y., Wang, W., Quan, Z., Wang, L., Yu, D., 2013. Experimental investigation of performance for the novel flat plate solar collector with micro-channel heat pipe array (MHPA-FPC). Appl. Therm. Eng. 54(2), 440-449.

Du, B., Hu, E., Kolhe, M., 2013. An experimental platform for heat pipe solar collector testing. Renew. Sust. Energy Rev. 17, 119-125.

Ersoz, M., 2016. Effects of different working fluid use on the energy and exergy performance for evacuated tube solar collector with thermosyphon heat pipe. Renew. Energy 96 244-256. Gunerhan, H., Hepbasli, A., 2007. Exergetic modeling and performance evaluation of solar water heating systems for building applications. Energy Build. 39 509-516. 
Guo, H., Du, H., Ye, F., Ma, C., 2010. Experimental Investigation of Solar Heat Pipes with Ethanol Solution as Working Fluid, 14th International Heat Transfer Conference. USA.

Han, J., Tian, R., Yan, S., 2009. Comparative analysis of the instantaneous efficiency about two types of solar collector. Energy Eng. 2, 25-27.

Hayek, M., Assaf, J., Lteif, W., 2011. Experimental investigation of the performance of evacuated tube solar collectors under eastern Mediterranean climatic conditions. Energy Proc. 6 618-626.

Holman, J.P., 2011. Experimental Methods for Engineers, 8th ed. McGraw-Hill.

Hussein, A.K., 2016. Applications of nanotechnology to improve the performance of solar collectors - Recent advances and overview. Renew. Sust. Energy Rev. 62, 767-792.

Hussein, H.M.S., El-Ghetany, H.H., Nada, S.A., 2006. Performance of wickless heat pipe flat plate solar collectors having different pipes cross sections geometries and filling ratios.

Energy Convers. Manage. 47 1539-1549.

Iranmanesh, S., Ong, H., Ang, B., Sadeghinezhad, E., Esmaeilzadeh, A., Mehrali, M., 2017. Thermal performance enhancement of an evacuated tube solar collector using graphene nanoplatelets nanofluid. J. Clean. Prod. 162 121-129.

Ismail, K., Abogderah, M., 1998. Performance of a heat pipe solar collector. Sol. Energy Eng. 120, 51-59.

Kumar, S.S., Kumar, K.M., Kumar, S.R.S., 2017. Design of Evacuated Tube Solar Collector with Heat Pipe. Materials Today: Proceedings 4, 12641-12646.

Loh, M., Coghlan, P., 2003. Domestic water use study in Perth. Water Corporation of WA, Western Australia.

Moffat, R.J., 1988. Describing the uncertainties in experimental results. Exp. Ther. Fluid Sci., 3-17.

Nkwetta, D.N., Smyth, M., 2012a. Comparative field performance study of concentrator augmented array with two system configurations. Appl. Energy 92, 800-808.

Nkwetta, D.N., Smyth, M., 2012b. Performance analysis and comparison of concentrated evacuated tube heat pipe solar collectors. Appl. Energy 98, 22-32.

Nkwetta, D.N., Smyth, M., 2012c. The potential applications and advantages of powering solar air-conditioning systems using concentrator augmented solar collectors. Appl. Energy 89(1), 380-386.

Pak, B.C., Cho, Y.I., 1998. Hydrodynamic and heat transfer study of dispersed fluids with submicron metallic oxide particles. Experimental Heat Transfer an International Journal 11(2), 151-170.

Reay, D., Kew, P., 2013. Heat pipes. Elsevier Science Ltd.

Saad, A.-M., Saleh, M., Ahmed, H.A., 2013. Evaluation of convective heat transfer and natural circulationin an evacuated tube solar collector. J. Eng. 19 613-628.

Sabiha, M., Saidur, R., Hassani, S., Said, Z., Mekhilef, S., 2015. Energy performance of an evacuated tube solar collector using single walled carbon nanotubes nanofluids. Energy

Convers. Manage. 105, 1377-1388.

Shafieian, A., Khiadani, M., Nosrati, A., 2018. A review of latest developments, progress, and applications of heat pipe solar collectors. Renew. Sust. Energy Rev. 95, 273-304.

Shafieian, A., Khiadani, M., Nosrati, A., 2019a. Strategies to improve the thermal performance of heat pipe solar collectors in solar systems: A review. Energy Conversion and Management 183, 307-331.

Shafieian, A., Khiadani, M., Nosrati, A., 2019b. Thermal performance of an evacuated tube heat pipe solar water heating system in cold season. Appl. Therm. Eng. 149, 644-657.

Sharafeldin, M., Grof, G., 2018. Evacuated tube solar collector performance using CeO2/water nanofluid. J. Clean. Prod. 185 347-356. 
Wei, L., Yuan, D., Tang, D., Wu, B., 2013. A study on a flat-plate type of solar heat collector with an integrated heat pipe. Sol. Energy 97, 19-25.

Xuan, Y., Roetzel, W., 2000. Conceptions for heat transfer correlation of nanofluids. International Journal of heat and Mass transfer 43(19), 3701-3707.

Yu, W., Xie, H., 2012 A review on nanofluids : preparation, stability mechanisms and applications. J. Nanomaterials(Article ID 435873), 1-17.

Zambolin, E., Col, D.D., 2010. Experimental analysis of thermal performance of flat plate and evacuated tube solar collectors in stationary standard and daily conditions. Sol. Energy 84 1382-1396.

Zhao, S., Xu, G., Wang, N., Zhang, X., 2018. Experimental Study on the Thermal Start-Up Performance of the Graphene/Water Nanofluid-Enhanced Solar Gravity Heat Pipe.

Nanomaterials 8, 1-16.

Zhou, S., Qi, Ni, R., 2008, Measurement of the specific heat capacity of water-based A12O3 nanofluid. Applied Physics Letter 92(9). 